Identifying the most significant indicators of the total road safety performance index

Peer-reviewed author version

Tesic, Milan; HERMANS, Elke; Lipovac, Krsto \& Pesic, Dalibor (2018) Identifying the most significant indicators of the total road safety performance index. In: ACCIDENT ANALYSIS AND PREVENTION, 113, p. 263-278.

DOI: 10.1016/j.aap.2018.02.003

Handle: http://hdl.handle.net/1942/26204 


\title{
IDENTIFYING THE MOST SIGNIFICANT INDICATORS OF THE TOTAL ROAD SAFETY
}

\section{PERFORMANCE INDEX}

\author{
Tešić Milan a,", Hermans Elke ${ }^{\mathrm{b}}$, Lipovac Krsto ${ }^{\mathrm{c}}$, Dalibor Pešić ${ }^{\mathrm{d}}$ \\ aThe Faculty of Transport and Traffic Engineering, Vojvode Stepe 305, 11000 Belgrade, Serbia, e-mail: milan.te.sicm@gmail.com \\ ${ }^{\mathbf{b}}$ Transportation Research Institute (IMOB), Hasselt University, Wetenschapspark 5 bus 6, 3590 Diepenbeek, Belgium, e-mail: \\ elke.hermans@uhasselt.be \\ ${ }^{\mathbf{c}}$ The Faculty of Transport and Traffic Engineering, Vojvode Stepe 305, 11000 Belgrade, Serbia, e-mail: k.lipovac@ @f.bg.ac.rs \\ d The Faculty of Transport and Traffic Engineering, Vojvode Stepe 305, 11000 Belgrade, Serbia, e-mail: d.pesic@ sf.bg.ac.rs
}

\begin{abstract}
The review of the national and international literature dealing with the assessment of the road safety level has shown great efforts of the authors who tried to define the methodology for calculating the composite road safety index on a territory (region, state, etc.). The procedure for obtaining a road safety composite index of an area has been largely harmonized. The question that has not been fully resolved yet concerns the selection of indicators. There is a wide range of road safety indicators used to show a road safety situation on a territory. Road safety performance index (RSPI) obtained on the basis of a larger number of safety performance indicators (SPIs) enable decision makers to more precisely define the earlier goal- oriented actions. However, recording a broader comprehensive set of SPIs helps identify the strengths and weaknesses of a country's road safety system. Providing high quality national and international databases that would include comparable SPIs seems to be difficult since a larger number of countries dispose of a small number of identical indicators available for use. Therefore, there is a need for calculating a road safety performance index with a limited number of indicators $\left(\mathrm{RSPI}_{\ln }{ }^{\mathrm{n}}\right.$ ) which will provide a comparison of a sufficient quality, of as many countries as possible. The application of the Data Envelopment Analysis (DEA) method and correlative analysis has helped to check if the $\mathrm{RSPI}_{\ln }{ }^{\mathrm{n}}$ is likely to be of sufficient quality. A strong correlation between the RSPI ${ }_{n}{ }^{n}$ and the RSPI has been identified using the proposed methodology. Based on this, the most contributing indicators and methodologies for gradual monitoring of SPIs, have been defined for each country analyzed. The indicator monitoring phases in the analyzed countries have been defined in the following way: Phase 1- the indicators relating to alcohol, speed and protective systems; Phase 2- the indicators relating to roads and Phase 3- the indicators relating to trauma management. This will help achieve the standardization of indicators including data collection procedures and selection of the key list of indicators that need to be monitored. Based on the results, it has been concluded that the use of the most contributing indicators will make it possible to assess the level of road safety on a territory, with an acceptable quality score by focusing on the low-ranked countries. A smaller set of significant indicators defined in this manner can serve for a fast and simple understanding of a road safety situation and assessment of effects of measures undertaken. Also, this universal index approach is applicable in cases when a broader comprehensive set of indicators is analyzed, which provides a more accurate identification of weaker points and rank the countries in a more meaningful way.
\end{abstract}

Keywords: road safety level, road safety performance index, most significant indicators, standardization

\section{Introduction}

Due to the multidisciplinary nature of road safety, the policy makers must consider numerous contributory factors when making decisions. A wide range of such contributory factors can be combined by applying the composite index which has been used increasingly in international cross-country comparisons. No final position on a methodology for road safety composite index design has been adopted yet globally. That is why numerous authors have been working hard to improve the methodologies and methods for the most

${ }^{*}$ Corresponding author: Tel: +387 66633458 (M. Tešić)

E-mail address: milan.te.sicm@gmail.com 
accurate definition of the composite index value. The accuracy of a composite index does not depend only on selected indicators, weight allocation and data aggregation methods, but also on the strength of correlation between indicators and road crashes and their consequences (Hermans et al., 2009b).

Various combinations of road safety indicators result in various values of a composite road safety index (and consequently a meaningful countries' rankings). This is particularly obvious with the design of the road safety footprint which contains a combination of indicators (all layers), measured as a snapshot in time (Wegman et al. 2008), and enabling the identification of strong and weak points within the road safety system (Wegman et al. 2005).This leads to the question: Which combination of road safety performance indicators gives a road safety performance index which is more precise, of higher quality and providing a simple understanding of a road situation? The answer to this question is open and requires much more research, with as many indicators included as possible in order to achieve the key list of road safety indicators which, regardless of the observed territory, gives the most realistic picture possible of the road safety situation. The key list of road safety indicators identified in this way offers support for decision makers to know which road safety topics they perform well or badly as a basis of improvements. The weakness of identification of a key list of road safety indicators within a wide comprehensive set of indicators is in the existence and strength of the correlative relationship of indicators and the final outcomes and their mutual relations (multivariate analysis), especially in cases when indicators that are not measured in several time series are introduced in an analysis. The lack of a harmonized methodology for a composite road safety index design has as a consequence diversity in selecting the road safety indicators and calculation methods. Therefore, the research conducted in this work focused on the selection of "the most significant safety performance indicators" (SPIs) involved in the process of calculating a "road safety performance index based on a limited number of indicators" in cases when data are not available or are scarce.

The studies that have been conducted so far helped to make the comparison of territories, define earlier goal-oriented actions and identify the best-in-class practices. The authors of these studies suggested creating a composite road safety index (Al- Haji, 2005, 2007; Wegman et al. 2008; Shen et al. 2015) by means of the most appropriate indicators, i.e. those having a high data availability and acceptability rate, as well as including as many indicators as possible, along with examining the robustness of the composite road safety index (Hermans et al, 2007, 2009b; Hermans, 2009a; Shen et al. 2011b). This is not so simple because indicator-related data in international and national bases are not always available and their definitions differ significantly. The compromise between the need (for as many indicators as possible) and the real situation (availability of only a limited number of indicators for specific countries) will mean identifying the most significant indicators (a comprehensive set of performance indicators). This set of indicators has the largest link with the final road safety rating. As the availability of data concerning the values of same indicators for a larger number of countries, in a defined time period is limited, the number of indicators included in a comprehensive set of indicators may vary. A composite index obtained on the basis of a broader comprehensive set of indicators provides a more accurate identification of good and poor road safety points on the territories. However, a composite road safety index with a limited number of indicators (obtained on the basis of a narrower comprehensive set of indicators) offers an adequate and efficient way of road safety monitoring and understanding and is an important driver for the development of a sustainable system of periodical measuring of indicators in low- ranked territories. The optimum selection of indicators allows for the simplest method of monitoring a road safety situation, comparing at the same time the largest number of territories possible.

The remaining of this paper is structured as follows: a short review of literature concerning the concept of a "composite index" in general and a "road safety performance index" is offered in Section 2.2. Section 3 gives a description of the study design, including: clearly given study objectives, basic concepts, data collection and selection of indicators. Relevant weighting and aggregation concepts are described in Section 4. Also, this section presents the methodology for identifying the most significant indicators. The results in terms of the correlative analysis, countries' ranking and identifying the most contributing indicators per country are discussed in Section 5. Section 6 is reserved for discussion of the most important results. This 
paper closes with the main recommendations for meaningful road safety performance index and conclusions and topics for further research.

\section{Literature review}

\subsection{Background of the composite index concept}

Saisana and Tarantola (2002) presented the methodology for designing a composite index, highlighting in particular methodological approaches and studies that have shown in which way and by means of which techniques a relevant composite index can be obtained for the observed criterion (for example: Human Development Index, Summary Innovation Index, Internal Market Index, Composite Leading Indicators, etc.). Later on, Saisana et al. (2005) made a step further and presented the technique of data uncertainty and sensitivity as a significant method for checking the quality of the obtained composite index. Further on, Nardo et al. (2005a) presented in detail and explained the process of selecting the indicators, techniques used for their processing and weight allocation methods and aggregation of indicators. They have also offered a detailed analysis of data uncertainty and sensitivity. The final deliverable of their work included a manual for making a composite index (Nardo et al., 2005b). This group of authors managed to classify the knowledge acquired until then and systematize the following issues: 1) steps for making a composite index; 2) frameworks for making a composite index while taking care of data availability, data relevance, usability of data, etc.; and 3) tools for defining a composite index (starting from the data processing techniques through normalization, to the weight allocation and aggregation of indicators methods and analysis of data uncertainty and sensitivity).

\subsection{The concept of a composite road safety index}

The states can improve their road safety on the basis of their experiences, systemic monitoring and crosscountry comparisons (Bax et al., 2012). In order to secure a systemic monitoring of road safety and comparisons with other countries, it will be necessary to undertake the process of selecting relevant road safety indicators which will represent the current road safety situation in the best possible and most accurate way (Pešić, 2012). The development of the scientific thought on road safety indicators has been running very quickly over the last decade (Al- Haji, 2005; Vis, 2005; Wegman et al., 2005; Hakkert and Gitelman, 2007a; Hakkert et al., 2007b; Hermans et al., 2007; Gitelman et al., 2014; Bastos, 2014a; Bastos et al., $\underline{2015}$, etc).

Several years ago, efforts have been put in establishing links among different countries world-wide. The inception phase has seen the comparison reports that dealt only with consequences of road crashes on the basis of which the countries used to compare their road safety levels. Further on, with the development and comprehension of road safety issues, methods for comparing road safety situations in specific areas have been also developed. In fact, academic circles have become aware that the road safety system is a multisectoral system dependent on multiple factors. Therefore, today's methods for road safety comparisons encompass a multitude of factors (and consequently a multitude of indicators) while tending to reduce all those indicators to the same scale and allocate them as most accurate weights possible to represent the specific features of the compared area. Depending on the purpose of the composite index, the phase of selecting the representative road safety indicators on a territory should start from the analysis of all categories (levels) of indicators from the Koornstra et al., 2002 and LTSA, 2000 pyramid. The pyramid identifies four levels of indicators (top-down), as follows: final outcomes (e.g. deaths per 100.000 inhabitants); intermediate outcomes (safety performance indicators); policy performance indicators (safety measures and programmes) and background performance indicators (structure and culture). Over the last couple of years, efforts have been made to identify correlations between certain "pyramid" levels, i.e. their influence on the final road safety assessment rate. It is possible to define a wide range of indicators for each "pyramid" level. The quality of the obtained composite index depends mostly on the level of diversity of definitions of these indicators, the quality of systems intended for their collection and the strength of their 
correlations with the final outcomes. In that case, the development of sustainable systems for periodical monitoring of a larger number of indicators, in a larger number of territories can be very demanding.

The SUNflower (Koornstra et al., 2002), SUNflower+6 (Wegman et al., 2005) and SUNflowerNext (Wegman et al., 2008) projects marked the momentum of the process of comparing countries' road safety levels. These projects essentially represent the platforms for cross-country comparisons according to selected criteria. The key problem arising from the interpretation of these results refers to the comparison of countries with various development levels, demographic and geographic features, etc. This problem has been overcome by grouping the countries with the same or nearly similar characteristics. Vis and Eksler (2008) have tried to resolve this issue by expanding the range of comparison criteria.

The next step of cross-country comparisons led to the grouping of relevant road safety indicators and their reduction to one common measure, i.e.to one value which will represent the road safety level (Al-Haji, 2005, 2007; Hermans, 2009a; Gitelman et al., 2010; Wegman and Oppe, 2010; Shen, 2011b; Bax et al., 2012; Pešić, 2013). The methods used to represent the level of road safety on a territory in the above papers form the basis of the modern concept of country comparisons in terms of their road safety.

The evolution of the idea of a road safety level assessment rate on a territory has been transformed into two phases. Phase 1 encompasses the authors who made the calculations for the composite index on the basis of indicators for only one layer (Hermans, 2009a; Shen et al., 2011a; Farchi et al., 2006; etc.). Phase 2 gathers together the authors who calculated their composite index on the basis of indicators of various layers (Wegman et al., 2005); Wegman et al., 2008; Wegman and Oppe (2010); Gitelman et al., 2010; Chen et al., 2016; Hermans et al., 2010a; etc.). In addition, there are works in the literature where the composite road safety sub-index is focused on one topic, for example: environment safety road index, alcohol index, etc. (Intan Suhana et al., 2014; Shen et al., 2014).

\section{Study design}

\subsection{Study objectives}

The main objective of this manuscript is to develop a scientifically sound and appropriate methodology for the creation of a road safety performance index with a limited number of indicators $\left(\mathrm{RSPI}_{\ln }{ }^{\mathrm{n}}\right)$ that can be used for the monitoring and comparison of road safety performance among countries. The Data Envelopment Analysis (DEA) method for optimization and selection of the most significant indicators (combination of five, four or just three safety performance indicators (SPIs)) has been used for that purpose. This methodology offers relevant, reliable, and comparable values of the $\mathrm{RSPI}_{\mathrm{ln}}{ }^{\mathrm{n}}$ having the strongest correlation with the RSPI obtained on the basis of the six selected SPIs. Depending on the type of RSPI ${ }_{\ln }{ }^{\mathrm{n}}$ a comparable analysis of countries' rankings has been made, highlighting the strength of the correlation with the mortality rate and the human development index, the two important indexes which have been linked to the RSPI before (Al- Haji, 2005; Hermans 2009a; Chen et al., 2016). The application of the above methodology has helped identify the most significant indicators in the total road safety performance index, on the basis of data measured as a snapshot in time. Also, it allows for a comparison of the largest number of countries possible and provides an adequate, simple and efficient way of road safety monitoring, which, on the other hand, generates actions for the development of a sustainable system for periodical measuring of indicators in low-ranked territories.

Therefore, the study has identified the most contributing indicators for the countries analyzed and will offer a proposal for monitoring the common combinations of indicators. Also, the study will offer standardization of indicators for the analyzed countries and selection of a key list of indicators for international comparisons or the benchmarking process. From a practical point of view, the analysis has shown that making credible comparisons of countries in conditions when the availability of data concerning the values of same indicators for a larger number of countries, in a defined time period, is rather limited, is possible by simply using the RSPI ${ }_{\ln }{ }^{n}$. 
The subject of this study is the continuation of the research conducted so far, by taking into account practical issues of scarce data. The methodology for calculating a road safety performance index with a limited number of indicators used in this paper is of universal and open nature, and is able to allow extension of data to be analyzed in three directions: 1) spatial: it is able to include a larger number of countries, regions, etc. (territories) by adding appropriate data; 2) temporal: it is possible to span more years (time series), and 3) quantitative: involvement of a larger number of indicators or different indicators. Having this in mind, this concept is valuable for the development of a road safety performance index. This reinforces the credibility, acceptability and future development of the road safety performance index with a limited number of indicators for this set of European countries.

\subsection{Basic concepts}

This section contains definitions of some basic concepts used throughout this manuscript.

- Mortality rate (abrr. MR) is the number of road fatalities in a country divided by the number of inhabitants living in that country (per 100,000 inhabitants);

- Safety Performance Indicators (abrr. SPIs) are the measures (indicators) reflecting those operational conditions of the road traffic system influencing the system's safety performance (Hakkert and Gitelman., 2007a);

- Road Safety Performance Index (abbr. RSPI) is a weighted combination of a set of Safety Performance Indicators.

The following definitions have been created for the purpose of this paper:

- Road Safety Performance Index with a limited number of SPIs (abrr. $\operatorname{RSPI}_{\ln }{ }^{\mathrm{n}}$ ) is a weighted combination of a limited number of SPI;

- Road Safety Performance Index with a limited number (three/ four/five) of SPIs (abrr. $\mathrm{RSPI}_{\mathrm{ln}}{ }^{3} / \mathrm{RSPI}_{\mathrm{ln}}{ }^{4}$ / $\mathrm{RSPI}_{1 \mathrm{n}}{ }^{5}$ ) is a combination of a limited number of three/ four/ five SPIs;

- Most significant indicators are a set of indicators which, when calculating the $\mathrm{RSPI}_{\ln }{ }^{\mathrm{n}}$, results in the largest correlation with the overall road safety performance index score (RSPI)

- Road Safety Performance Indicators based on the most contributing indicators per country (abbr. RSPI $\left.{ }_{m c i}{ }^{n}\right)$ is a combination of the most important set of indicators per country, and

- Most contributing indicators per country are a set of indicators having the largest share (i.e. the sum of product of each indicator value and its assigned weight) in the overall road safety performance index score.

\subsection{Collection and selection of indicators}

Attention should be paid to the collection of reliable data because the validity, interpretability and explanatory power of the constructed index depends on data quality and their completeness. The focus of this study is put on European countries with the aim of evaluating the road safety performance of countries with a comparable level of mobility development (i.e. countries characterized by a similar transport system and motorization rate). Nonetheless, a broader analysis on a worldwide scale may be interesting but availability of data concerning the values of same indicators for a larger number of countries, in a defined time period, makes a significant limitation. In addition to data availability, comparability of available data from the point of view of definitions and the manner of measuring them in the field is also disputable.

In the present study, data collection starts from the seven risk domains considered in the SafetyNet project (Vis, 2005) as it is the most recent source with respect to the following road safety performance indicators: alcohol and drugs, speed, protective systems, daytime running lights, vehicle, roads and trauma management. Each indicator used for the calculation of a road safety performance index represents one risk 
domain. "Best needed" and "best available" indicators for each risk domain are first identified in this phase. A "best needed indicator" is the ideal indicator while the "best available indicator" is the best possible indicator for which the available data are of acceptable quality (based on selection process in Hermans, 2009a). The performance of countries with respect to daytime running lights is not captured by this indicator, as the nature of this indicator distinguishes only three possible values (countries with the mandatory use of DRL on all roads during the entire year; countries with the mandatory use of DRL on some roads and/or during some periods of the year; and countries enacting no DRL law) and the classification is characterized by some level of uncertainty. Therefore, it is decided not to incorporate the indicator for the daytime running lights domain in the index construction process.

The subject of analysis includes the following 6 road safety performance indicators that have been collected on the basis of a selection process: (SPI_1) \% of surveyed car drivers < BAC (Blood Alcohol Concentration limit); (SPI_2) \% of surveyed car drivers < speed limit in urban areas; (SPI_3) seat belt wearing rate at front seats of cars and vans; (SPI_4) \% of cars < 6 years; (SPI_5) density of motorways and (SPI_6) total health expenditure as a \% of GDP. The available data relating to the SPIs were collected and compiled from some international databases and several recent publications, or more specifically for (SPI_1) (SARTRE, 2004), (SPI_2) (SARTRE, 2004), (SPI_3) (ETSC, 2006), (SPI_4) (Eurostat, 2008), (SPI_5) (Eurostat, 2007) and (SPI_6) $(\underline{W H O, 20096})$. Data collected for each indicator belong to the period [2002; 2008]. The number of road fatalities per million inhabitants has been used for the final outcome level because it is characterized by a high degree of comparability and data availability. The 2003 values presented in the report of the European Union Road Federation (2006) have been also used. Data are available for 20 of the 21 countries considered in this study. For Switzerland, the number of fatalities per million inhabitants is deduced from the Organisation for Economic Co-operation and Development (2008).

The data set of the core set of basic road safety performance indicators (SPIs) was available for only 21 European countries (20 EU Member States plus Switzerland), specifically including Austria (AT), Belgium (BE), Switzerland (CH) Cyprus (CY), Czech Republic (CZ), Denmark (DK), Estonia (EE), Finland (FI), France (FR), Germany (DE), Greece (EL), Hungary (HU), Ireland (IE), Italy (IT), the Netherlands (NL), Poland (PL), Portugal (PT), Slovenia (SL), Spain (ES), Sweden (SE) and the United Kingdom (UK).

Table 3.1 offers the values with respect to the central tendency and distribution. Focusing on the eg. Protective systems indicator, it can be seen that the seat belt wearing rate in the front seats of cars and vans is $79.6 \%$ on average in those 21 countries. Moreover, the most frequent value in the data set is $75 \%$, while the median equals $82 \%$. The intervals [40;75], [75; 82], [82;88] and [88;97] contain one quarter of the observations. A variance of 175.8 or a standard deviation of 13.3 implies a considerable variability in the protective systems data.

\section{Table 3.1}

Summary statistics on the indicator data

\begin{tabular}{lrrrrrr}
\hline & SPI_(1) & SPI_(2) & SPI_(3) & SPI_(4) & SPI_(5) & SPI_(6) \\
\hline \# of cases & 21 & 21 & 21 & 21 & 21 & 21 \\
\hline Mean & 96.10 & 92.38 & 79.57 & 34.48 & 1.95 & 8.52 \\
\hline Modus & 99.7 & 94 & 75 & $/$ & 2 & 7.5 \\
\hline Median & 97.5 & 93 & 82 & 36.74 & 2 & 8.4 \\
\hline $25^{\text {th }}$ Percentil & 94.9 & 89 & 75 & 28.69 & 0.6 & 7.5 \\
\hline $75^{\text {th }}$ Percentil & 98.7 & 94 & 88 & 39.43 & 2.4 & 9.6 \\
\hline Minimum & 78.2 & 88 & 40 & 17.01 & 0.1 & 5.3 \\
\hline Maximum & 100 & 97 & 97 & 53.67 & 6.1 & 11.5 \\
\hline Range & 21.8 & 9 & 57 & 36.66 & 6 & 6.2 \\
\hline Variance & 22.80 & 10.05 & 175.76 & 99.25 & 2.82 & 2.47 \\
\hline St. deviation & 4.78 & 3.17 & 13.26 & 9.96 & 1.68 & 1.57 \\
\hline
\end{tabular}

All indicators point in the same direction as this is crucial in the creation of an index. In other words, a high indicator value should always imply more (or less) casualties. Indicators' values have been normalized using the re-scaling method. This procedure normalizes the indicators so that they all have identical range (0 1), (Nardo et al., 2005b). 
Beside a spatial boundary, the data set used in this study is limited in time. As no data are available for all indicators over some period of time, the road safety performance index will be computed for one year only (as a snapshot in time). Data unavailability is a common limitation for all studies dealing with country comparisons from the road safety point of view. This limitation is particularly highlighted in case of data on safety performance index. The fact is that "safety performance indicators" were introduced for the first time only in 2001 (ETSC, 2001). The most recent source with respect to road safety performance indicators offering all the comprehensive definitions and the key list of indicators is the SafetyNET project (Vis, 2005). From the studies of Al-Haji, 2005, 2007; Hermans, 2009a, then Gitelman et al., 2010; Wegman and Oppe, 2010; Shen, 2011b, up until Bax et al., 2012; Pešić, 2012 etc., data availability represents a practical obstacle especially in road safety domains such as: "alcohol and drugs" and "speed". All those mentioned authors used data from various international databases, diverse studies and research, etc.

Existing international databases, such as International Road Traffic and Accident Database (IRTAD), Community Road Accident Database (CARE), Eurostat, EURF, etc., contain a larger volume of data on final outcomes and some data for vehicle fleet structure and age, road lenght and motorways density, health expenditure, etc. Some countries (United Kingdom, Sweden, Serbia, etc.) have national good quality indicator's databases. Even though a certain number of countries monitors the road safety performance indicators, the manners of measuring and defining these indicators are different which questions the comparability of these data, i.e. the credibility of the composite index.

From a theoretical point of view, a larger number of indicators provide a road safety performance index of higher quality by means of which decision makers are able to more precisely define the earlier goal-oriented actions. Or, by recording a broader comprehensive set of SPIs it is possible to more precisely identify the strengths and weaknesses of a country's road safety system. However, from the point of view of practical use, a road safety performance index with a limited number of indicators will have to be calculated, which will in turn provide comparisons of higher quality and accuracy and an efficient way of road safety monitoring.

\section{Methodology}

The calculation in this paper has been made using the methodology for developing a composite road safety performance index for cross-country comparisons, developed by Hermans, 2009a. This methodology consists of several steps: 1) Selecting the appropriate indicators to combine them in an index; 2) Collecting the data on indicators; 3) Making of data analyses; 4) Assigning the weights to each indicator; 5) Aggregating the values of indicators; 6) Testing the robustness of the index and 7) Computing, evaluating and visualizing the scores of the final index. This methodology has been applied to create a composite road safety performance index relating to the intermediate outcome layer.

The text below offers the presentation of the following two most important steps for the calculation of a composite index with a limited number of indicators: the weighting method and the aggregating indicators.

\subsection{Weighting method}

One of the most significant steps in the process of composite index calculation is "Assigning the weights to each indicator". After the selection of the set of indicators has been made, the selection of a weight allocation method is the most important factor having limited interaction effects with other input factors. Out of five weighting methods used, the data envelopment analysis (DEA) method has resulted in a ranking which best approaches the final outcome ranking based on the number of road fatalities per million inhabitants (Hermans et al., 2008b). The Data envelopment analysis (DEA), originally developed by Charnes, Cooper, and Rhodes in 1978, is a non-parametric mathematical optimization technique used to assess the relative efficiency of a homogeneous set of decision-making units (DMUs), on the basis of multiple inputs and multiple outputs. The heart of the DEA analysis lies in the finding of best DMUs, viewed as the most efficient ones under the given circumstances and used to construct the so-called efficient

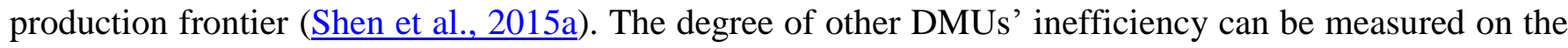


basis of their distance from the frontier. For more information on this technique, we refer to Charnes et al.,

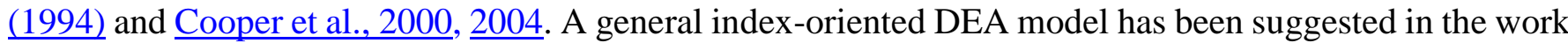
of Cherchye et al., (2006). For each country, there can be obtained a composite index score between zero and one, with higher values indicating a better relative performance. From the point of view of index scores, the best performing (efficient) countries are those having an objective value of one. At the same time, the index scores of underperforming (inefficient) countries lie between zero and one. For the countries having an optimal composite index score smaller than one, the country-specific weights are able to identify the problem areas.

\subsection{Aggregating indicators}

\subsubsection{General Concepts}

The Ordered Weighted Averaging (OWA) operators are used as an expert method for data aggregation. OWA functions are the second type of common averaging aggregation functions. They have been introduced by Yager (1988). It is important to note that the weights in weighted means and in OWA functions represent different aspects. In case of OWA, a weight is no longer associated with the meaning of a particular criterion (or indicator) - such as the alcohol and drugs weight - but with its magnitude. More specifically, OWA operators assigning weights to magnitudes of performances appear to be useful aggregation operators since good and bad performance can have a different contribution to the index score.

Very common aggregation operators include maximum, minimum and arithmetic mean. The weighting vector $\vec{w}$ of these operators is given: 1$) \max : \vec{w}=(1,0, \ldots, 0)$ and considers only the best performance; 2$)$ min: $\vec{w}=(0, \ldots, 0,1)$ and considers only the worst performance and 3$)$ arithmetic mean: $\vec{w}=$ $(1 / n, 1 / n . ., 1 / n)$ considering each performance equally. One of the methods for obtaining relevant OWA weights is the "orness" concept. The degree of orness corresponds to the degree of optimism of a decision maker (Yager, 1997). For an OWA weighting vector, the degree of orness is defined as shown in Eq. 4.1.

$\operatorname{orness}\left(\overrightarrow{w)}=\frac{1}{l-1} \sum_{i=1}^{l}(l-i){\overrightarrow{w_{l}}}_{l}=\frac{1}{l-1} \sum_{i=1}^{l-1}(l / i)^{\alpha}\right.$

$\overrightarrow{w_{l}}=Q\left(\frac{i}{l}\right)-Q\left(\frac{i-1}{l}\right)$ for $i=1, \ldots, l$

$Q(r)=r^{\alpha}$ with $\alpha \geq 0$

In case of six indicators, the above formulas result in:

$\overrightarrow{w_{1}}=\left[\frac{1}{6}\right]^{\alpha} ; \overrightarrow{w_{2}}=\left[\frac{2}{6}\right]^{\alpha}-\left[\frac{1}{6}\right]^{\alpha} ; \overrightarrow{w_{3}}=\left[\frac{3}{6}\right]^{\alpha}-\left[\frac{2}{6}\right]^{\alpha}$;

$\overrightarrow{w_{4}}=\left[\frac{4}{6}\right]^{\alpha}-\left[\frac{3}{6}\right]^{\alpha} ; \overrightarrow{w_{5}}=\left[\frac{5}{6}\right]^{\alpha}-\left[\frac{4}{6}\right]^{\alpha} ; \overrightarrow{w_{6}}=\left[\frac{6}{6}\right]^{\alpha}-\left[\frac{5}{6}\right]^{\alpha}$

In terms of road safety, $\alpha$ represents the degree to which the occurrence of road fatalities depends on the magnitude of the six performances. For an $\alpha$ equal to one, the number of road fatalities per million inhabitants is considered to result equally from good and bad performances. The value of $\alpha$ that is larger (smaller) than one implies that the worst (best) performances affect the number of road fatalities more and therefore low (high) indicator values are emphasized in that case.

\subsubsection{Linguistic formulations}

In order to incorporate the aggregation idea that is deduced by means of linguistic formulations, i.e. to punish bad performances, by a panel discussion, the following principles regarding aggregation were gathered:

- In case a country scores badly on more than a few indicators, its final road safety index score should be small. In this case: minimum two or $40 \%$ of the total number of indicators, and 
- In case a country scores badly on a few indicators, its final road safety index score should be between small and average. In this case: maximum two or $40 \%$ of the total number of indicators.

The first step in transforming the guidelines into restrictions for $\alpha$ is to give a specific meaning to the concepts 'badly' (with respect to indicator performance), 'a few' (with respect to the number of indicators), 'small' and 'average' (with respect to the index score). With respect to a specific indicator, performance will be classified as 'good', 'average' or 'bad'. Here, score 1 is assigned to good; score 0.5 to average and score 0 to bad performances. On a total of six indicators, 'a few' corresponds to two; 'most' to four and 'almost all' to five. A 'small' index score is 0.25 at the most, an 'average' index score corresponds to 0.5 whereas a 'large' index score is at least 0.75. By using (Eq. 4.2), restrictions for $\alpha$ can be deduced.

$f_{\alpha}(1,1,1,0,0,0) \leq 0.25$ (Small index score)

$\Leftrightarrow \overrightarrow{w_{1}}+\overrightarrow{w_{2}}+\overrightarrow{w_{3}} \leq 0.25$ (More than two indicators are bad $=$ three indicators are good)

$\Leftrightarrow\left[\frac{1}{6}\right]^{\alpha}+\left[\frac{2}{6}\right]^{\alpha}-\left[\frac{1}{6}\right]^{\alpha}+\left[\frac{3}{6}\right]^{\alpha}-\left[\frac{2}{6}\right]^{\alpha}<0.25$

$\Leftrightarrow\left[\frac{1}{2}\right]^{\alpha} \leq 0.25$

$\Leftrightarrow \alpha \geq 2$

$0.25<f_{\alpha}(1,1,1,0.5,0,0)<0.5$ (Index score lying between small $(0.25)$ and average $(0.5)$ )

$\Leftrightarrow 0.25<\overrightarrow{w_{1}}+\overrightarrow{w_{2}}+\overrightarrow{w_{3}}+0.5 \times \overrightarrow{w_{4}}<0.5$ (Two indicators are bad $=$ three indicators are good and one indicator has an average score)

$\Leftrightarrow 0.25<\left[\frac{1}{6}\right]^{\alpha}+\left[\frac{2}{6}\right]^{\alpha}-\left[\frac{1}{6}\right]^{\alpha}+\left[\frac{3}{6}\right]^{\alpha}-\left[\frac{2}{6}\right]^{\alpha}+0.5 \times\left[\left(\frac{4}{6}\right)^{\alpha}-\left(\frac{3}{6}\right)^{\alpha}\right]<0.5$

$\Leftrightarrow 0.25<0.5 \times\left(\frac{3}{6}\right)^{\alpha}+0.5 \times\left(\frac{4}{6}\right)^{\alpha}<0.5$

$\Leftrightarrow 1.2946<\alpha<2.6526$

Based on (Eq. 4.3) and (Eq. 4.4) we can conclude that $\alpha$ should be in the interval $[2 ; 2.65]$ to aggregate the six indicators in a way that is acceptable for the experts. The orness value in the interval $[0.236 ; 0.306]$ is obtained by inserting the limit values of $\alpha$ in Eq. 4.1. The selected value of $\alpha$ producing the strongest relation with the ranking is based on the number of road fatalities per million inhabitants. The result is the value of $\alpha$ equal to 2.0 and an OWA vector of $(0.03 ; 0.08 ; 0.17 ; 0.27 ; 0.42 ; 0.58)$.

Reflecting on the experts and decision makers' attitudes is very useful in this respect. Translating their verbal preferences with respect to compensational behavior into a smaller number of $\alpha$, using a few computations, increases the reliability of the final road safety index (Hermans et al., 2010b). Because of that, this method is the most useful aggregation operator for the road safety index case because it enables the experts/decision makers/stakeholders at the national level to agree on the linguistic formulation for the purpose of this aggregation method. This also provides a higher degree of acceptability of the results obtained, which opens the door to the definition of the earlier goal-oriented actions.

\subsection{Index methodology}

To obtain the final road safety performance index scores, it is necessary to have a decision concerning indicator selection, normalization, weighting and aggregation. These steps have been dealt with in the previous sub-headings. Eq. 4.5 represents the algebraic model used to compute the final road safety performance index score (RSPI) for a country $\mathrm{j}(j=1, \ldots, n)$ : 
$R S P I_{j}=\frac{\max }{w_{l j}} \sum_{i=1}^{l} \overline{r_{l j}} \overline{w_{l \jmath}}$

s.t.

$$
\begin{aligned}
& \sum_{i=1}^{l} \overline{w_{l \jmath}}=1 \\
& 0.236 \leq \frac{1}{l-1} \sum_{i=1}^{l}(l-1) \overline{w_{l \jmath}} \leq 0.306 \\
& L_{m} \leq \frac{r_{m j} w_{m j}}{\sum_{i=1}^{l} \overline{r_{l \jmath}} \overline{w_{l \jmath}}} \leq U_{m} \\
& \overline{w_{l j}} \geq 0
\end{aligned}
$$

With $1=$ number of indicators

- $=$ ordered value

$\mathrm{r}=$ rescaled value

$\mathrm{w}=$ weight

$\mathrm{m}=\{$ alcohol; speed; protective system; vehicle; road; trauma management $\}$

$\mathrm{L}=$ lower limit

$\mathrm{U}=$ upper limit

As shown in (Eq. 4.5), the road safety performance index score of a country consists of the ordered rescaled indicator values (i.e. values between zero and one, in decreasing order) and ordered weights (i.e. the first weight is corresponding to the best performance). More specifically, the share of each of the six indicators in the total index score was restricted by a lower and upper limit, using the budget allocation weights from a panel of experts.

\section{Table 4.1}

Lower and upper limits for the share of each indicator in the overall input

\begin{tabular}{lrr}
\hline Indicators & Lower limit & Upper limit \\
\hline \% of surveyed car drivers < BAC & 0.077 & 0.371 \\
\hline \% of surveyed car drivers < speed limit in urban areas & 0.149 & 0.488 \\
\hline seat belt wearing rate at front seats of cars and vans & 0.072 & 0.297 \\
\hline \% of cars < 6 years & 0.022 & 0.149 \\
\hline density of motorways & 0.015 & 0.277 \\
\hline total health expenditure as a \% of GDP & 0.022 & 0.239 \\
\hline
\end{tabular}

The weights obtained by calculating the RSPI are used for the calculation of $\mathrm{RSPI}_{l n}{ }^{3}, \mathrm{RSPI}_{l n}{ }^{4}$ and $\mathrm{RSPI}_{l n}{ }^{5}$ for the purpose of this study, since the program could not find a feasible solution. The reason for that is the reduction in the space for searching an optimum solution based on three or four indicators. Furthermore, along with the fixed indicator weights for each country, it was necessary to use the linear aggregation (additive aggregation) method for the calculation of the $\mathrm{RSPI}_{\ln }{ }^{\mathrm{n}}$. The mentioned aggregation method has been used following the recommendations of Nardo et al., 2005a and those of Pešić, 2012, who made a test in which the linear aggregation method, based on pre-defined criteria, scored the best result.

Depending on the value of their road safety performance index, the countries have been assigned a specific level of $\mathrm{RSPI}_{\mathrm{ln}}{ }^{\mathrm{n}}$ in the following way: 1) High RSPI -countries with a value over $0.500 ; 2$ ) Average RSPIcountries with a value from 0.307 to 0.499 ; and 3) Low RSPI - countries with a value under 0.306 . The index score is bounded by the highest and lowest indicator's value and has been made using the ordered weighted averaging (OWA) operators.

A system of "indicator combinations" with three, four and five indicators has been designed for the calculation of the $\mathrm{RSPI}_{l n} \mathrm{n}$. The formula (Eq. 4.6) serves to determine the total number of indicator combinations for the calculation of values of a road safety performance index: 
$C_{k}^{n}=\left(\begin{array}{l}n \\ k\end{array}\right)=\frac{n !}{k !(n-k) !}=\frac{n \cdot(n-1) \cdots(n-k+1)}{k \cdot(k-1) \cdots 1}, n \geq k \geq 0,(n, k) \in N$

- Total number of combinations $\left(\begin{array}{l}6 \\ 3\end{array}\right)$, the value of $\mathrm{RSPI}_{\ln }{ }^{3}$ is calculated for 20 combinations;

- Total number of combinations $\left(\begin{array}{l}6 \\ 4\end{array}\right)$, the value of $\mathrm{RSPI}_{\ln }{ }^{4}$ is calculated for 15 combinations, and

- Total number of combinations $\left(\begin{array}{l}6 \\ 5\end{array}\right)$, the value of $\operatorname{RSPI}_{\ln }^{5}$ is calculated for 6 combinations.

The flow chart of the calculated values of the road safety performance index with a limited number of SPIs is shown in Fig. 1 and consists of several steps.

\section{Fig.1.}

A flowchart on the calculation of road safety performance index scores based on SPI combinations

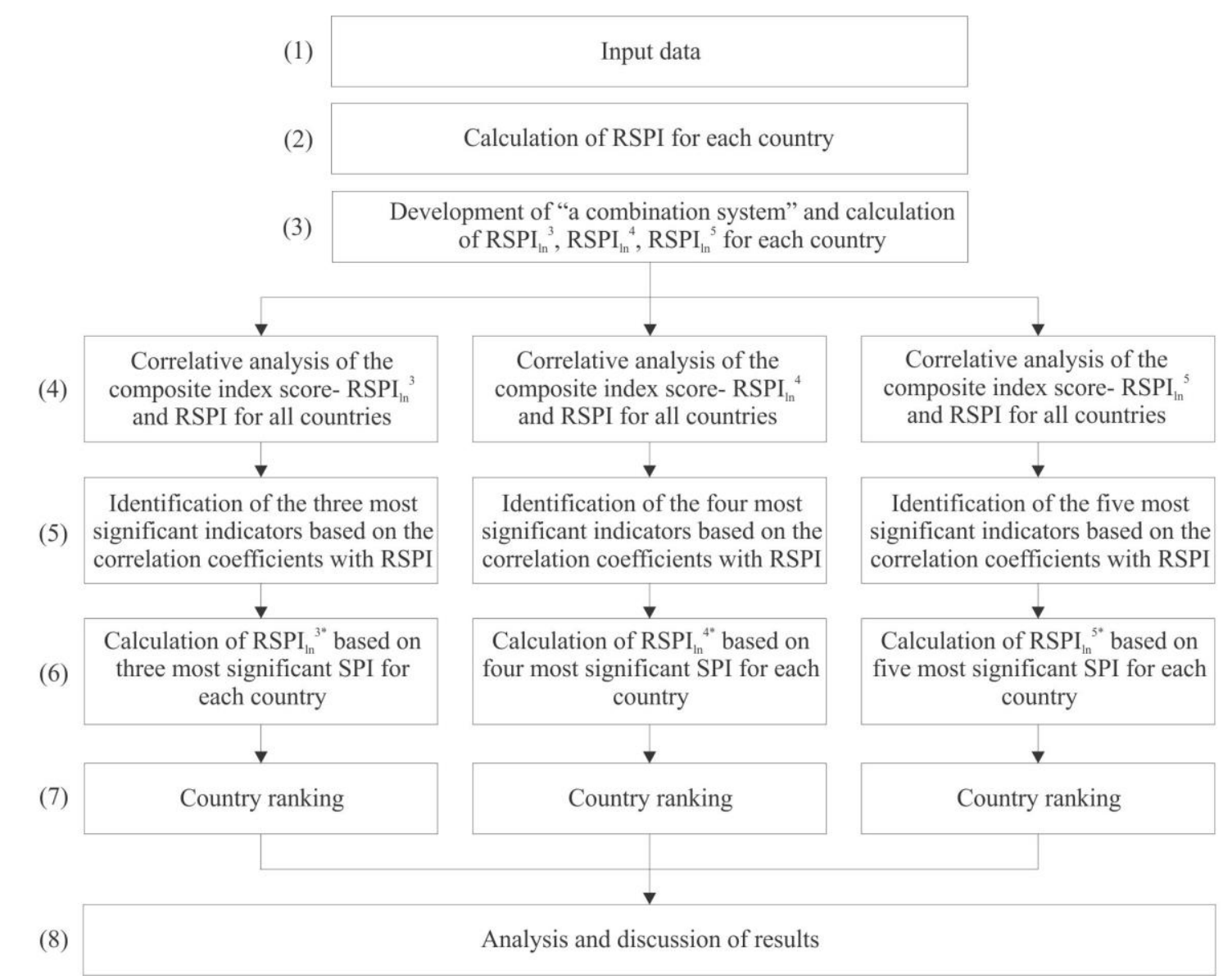

A more detailed explanation of the above steps for the calculation of a road safety performance index based on the combination of SPIs is given in the text below.

Step_1: A previously made Excel sheet with the values of the six SPIs is imported into the program.

Step_2: The value of RSPI is calculated for all 21 countries. IBM CPLEX is used to solve the road safety performance index algorithm. The algorithm for the calculation of the RSPI according to Hermans, 2009a is a methodology written according to the rules of the program's syntax.

Step_3: The system of "indicator combinations" has been created accordingly, along with the calculation of values of $\mathrm{RSPI}_{l n}{ }^{3}, \mathrm{RSPI}_{\mathrm{ln}}{ }^{4}$ and $\mathrm{RSPI}_{\mathrm{ln}}{ }^{5}$.

Step_4: A correlation analysis helped determine the correlation level between the two variables for all three cases: 1) $\mathrm{RSPI}_{\mathrm{ln}^{3}}{ }^{3}$ and RSPI for all countries, 2) $\mathrm{RSPI}_{\mathrm{ln}^{4}}{ }^{4}$ and RSPI for all countries, 3) $\mathrm{RSPI}_{\mathrm{ln}^{5}}{ }^{5}$ and RSPI for all countries. 
Step_5: Based on the correlation coefficients with RSPI, the most significant three, four and five indicators have been identified.

Step_6: The values of $\operatorname{RSPI}_{\ln }{ }^{3 *}, \operatorname{RSPI}_{\ln }{ }^{4 *}$ and $\mathrm{RSPI}_{\ln }{ }^{5^{*}}$ have been calculated for all countries on the basis of the most significant indicators of the dataset from the previous step.

Step_7: Country ranking according to the value of the road safety performance index score with a limited number of indicators ( $\operatorname{RSPI}_{\ln }{ }^{3 *}, \mathrm{RSPI}_{\ln }{ }^{*}$ and $\mathrm{RSPI}_{\ln }{ }^{5^{*}}$ ) has been also made.

Step_8: Analysis and discussion of results

Based on previous steps, a list has been made of the most contributing three, four and five indicators per country that should be regularly monitored and combined into a high quality road safety performance index (Subheading 5.3).

\section{Results}

The results obtained in this study will be discussed in 3 parts. Based on the correlation strength between the RSPI ${ }_{l n}{ }^{n}$ and RSPI, the most significant indicators for 21 countries have been first identified. In addition, the change in the country ranking depending on the most significant three, four and five indicators based on OWA operators has been also analyzed. The values of $\mathrm{RSPI}_{\mathrm{ln}}{ }^{\mathrm{n}} *$ have been compared using the mortality rate and the human development index, as a relevant reference. Finally, the optimization model revealed the most contributing indicators per country, which helped recognize the indicator monitoring phases for all analyzed countries (standardization of indicators), as a basis, and selection of a key list of indicators for international comparisons or the benchmarking process, in conditions when the availability of data concerning the values of same indicators for a larger number of countries, in a defined time period, is rather limited.

\subsection{Correlative analysis between the $\operatorname{RSPI}_{l n}{ }^{n}$ and $R S P I$}

The application of Spearman's correlation analysis of the results obtained by calculating the road safety performance index for various combinations of three, four and five indicators and the composite index obtained on the basis of all six indicators has helped obtain the results shown in Table 5.1. Column 1 contains the combination of indicators marked by SPI codes and sorted by correlation coefficient values from Column 2. Cohen, 1988 (taken over from Pallant, 2011) has ranked the correlation values in the following way: 1) small correlation $(\mathrm{r}=.100-.299)$; medium correlation $(\mathrm{r}=.300-.499)$ and large correlation $(\mathrm{r}=.500-1.000)$. Based on these guidelines for correlation interpretation, it is possible to conclude that among the road safety performance index values ( $\mathrm{RSPI}_{l n}{ }^{3}$ ), only the combination of "protective system, vehicle and trauma management" (abbr.: 3_4_6) has a medium correlation $(\mathrm{r}=.471$, $\mathrm{p}=.01)$, while all other values of $\operatorname{RSPI}_{\ln }{ }^{3}$ have a large correlation with the value of $\operatorname{RSPI}(\mathrm{r} \geq .50, \mathrm{p}=.01)$. The most significant indicators are "speed, roads and trauma management" (abbr.: 2_5_6), giving the highest value for the correlation coefficient $(\mathrm{r}=.906, \mathrm{p}=.01)$ amongst the values of composite index $\mathrm{RSPI}_{\mathrm{n}}{ }^{3}$ and the value of RSPI for 21 countries.

\section{Table 5.1}

The most significant indicators based on Spearman's rho (rank correlation coefficient) with the RSPIs

\begin{tabular}{|c|c|c|c|c|c|}
\hline Column 1 & Column 2 & Column 3 & Column 4 & Column 5 & Column 6 \\
\hline $\begin{array}{c}\text { RSPI }^{3}{ }^{3} \\
(\text { SPI code }) \\
\end{array}$ & $\begin{array}{l}\text { Rank based } \\
\text { on } \mathbf{r} \text { values }\end{array}$ & $\begin{array}{c}\mathrm{RSPI}_{\mathbf{l n}}{ }^{4} \\
\text { (SPI code) }\end{array}$ & $\begin{array}{c}\text { Rank based } \\
\text { on } r \text { values }\end{array}$ & $\begin{array}{c}\mathrm{RSPI}_{\text {In }}{ }^{5} \\
(\mathrm{SPI} \text { code) }\end{array}$ & $\begin{array}{l}\text { Rank based } \\
\text { on } \mathbf{r} \text { values }\end{array}$ \\
\hline 2_5_6 & 0.906 & 1_2_5_6 & 0.958 & 1_2_3_5_6 & 0.994 \\
\hline $2 \_3 \_5$ & 0.905 & 1_2_3_6 & 0.936 & 1_2_3_4_5 & 0.957 \\
\hline 2_3_6 & 0.878 & 2_3_5_6 & 0.931 & 1_2_4_5_6 & 0.957 \\
\hline 1_2_5 & 0.871 & 1_2_3_5 & 0.927 & 1_2_3_4_6 & 0.948 \\
\hline 1_5_6 & 0.866 & 2_3_4_5 & 0.912 & 2_3_4_5_6 & 0.927 \\
\hline $2 \_4 \_5$ & 0.856 & 1_2_4_5 & 0.895 & 1_3_4_5_6 & 0.821 \\
\hline
\end{tabular}




\begin{tabular}{|c|c|c|c|c|}
\hline & 2_3_4 & 0.848 & 1_4_5_6 & 0.891 \\
\hline & 1_2_3 & 0.842 & 2_4_5_6 & 0.866 \\
\hline & 1_2_6 & 0.803 & $2 \_3 \_4 \_6$ & 0.852 \\
\hline & 1_4_5 & 0.801 & 1_2_4_6 & 0.848 \\
\hline & 2_4_6 & 0.792 & 1_2_3_4 & 0.829 \\
\hline & 1_3_6 & 0.751 & 1_3_5_6 & 0.825 \\
\hline & 1_3_5 & 0.726 & 1_3_4_5 & 0.777 \\
\hline & 4_5_6 & 0.710 & 1_3_4_6 & 0.749 \\
\hline & 1_4_6 & 0.694 & 3_4_5_6 & 0.669 \\
\hline & 1_2_4 & 0.681 & & \\
\hline & 3_5_6 & 0.666 & & \\
\hline & 3_4_5 & 0.626 & & \\
\hline & 1_3_4 & 0.536 & & \\
\hline & 3_4_6 & 0.471 & & \\
\hline \multirow[t]{6}{*}{ SPI codes: } & \multicolumn{4}{|c|}{1 Alcohol: \% of surveyed car drivers $<$ BAC limit } \\
\hline & \multicolumn{4}{|c|}{2 Speed: \% of surveyed car drivers $<$ speed limit in built-up areas } \\
\hline & \multicolumn{4}{|c|}{3 Protective system: seat belt wearing rate at front seats of cars and vans } \\
\hline & \multicolumn{4}{|c|}{$4 \quad$ Vehicle: $\%$ of cars $<6$ years } \\
\hline & \multicolumn{4}{|c|}{5 Roads: density of motorways } \\
\hline & \multicolumn{4}{|c|}{6 Trauma management: total health expenditure as GDP\% } \\
\hline
\end{tabular}

When looking at Columns 3 and 4 in Table 5.1, it can be noticed that all the combinations of indicators of $\mathrm{RSPI}_{\mathrm{ln}}{ }^{4}$ offer a large correlation ( $\mathrm{r} \geq .500, \mathrm{p}=.01$ for all combinations) with the RSPI. The most significant four indicators are "alcohol, speed, roads and trauma management" (abbr.: 1_2_5_6), having a correlation coefficient of $r=.958$. Finally, Columns 5 and 6 show the ranking of values for $\mathrm{RSPI}_{\ln }{ }^{5}$ with the RSPI. The correlation coefficient of the combination with five indicators is extremely large ( $r>900)$. The most significant five indicator combination is the one with "alcohol, speed, protective system, roads and trauma management" where $r=.994$ (almost complete congruence of values of the composite index $\operatorname{RSPI}_{\ln }{ }^{5}$ with the RSPI). Regardless of which indicator combination is in question, the strength of the correlation with the RSPI is extremely large, with the exception of the combination 3_4_6 which is ranked as medium correlation.

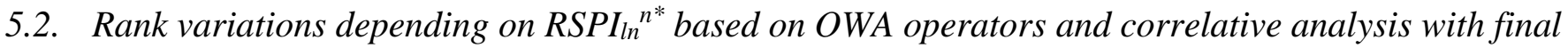 outcomes}

The value of a road safety performance index has been calculated for the most significant three, four and five indicators, on the basis of which the countries have been ranked. The countries are grouped within obtained classes and the standard deviation of countries' rankings on the basis of different $\mathrm{RSPI}_{\ln }{ }^{\mathrm{*}}$ has been also calculated. Looking at AppendixB.1, it can be clearly seen that there are certain deviations in country ranking on the basis of values of a road safety performance index with a limited number of indicators $\left(\mathrm{RSPI}_{\mathrm{ln}}{ }^{3 *}, \mathrm{RSPI}_{\mathrm{ln}}{ }^{4 *}\right.$ and $\left.\mathrm{RSPI}_{\mathrm{ln}}{ }^{5 *}\right)$ and a road safety performance index obtained on the basis of all indicators (RSPI). Having paid due respect to expert decisions contained in the ordered weighting averaging operators method, it is clear that no country belongs to the group of countries with a high RSPI score (Column 1). In fact, only six countries have the value of $\mathrm{RSPI}_{\mathrm{ln}^{3}}{ }^{3 *}$ higher than 0.306 , while the remaining 15 countries have a lower value of $\mathrm{RSPI}_{\mathrm{ln}}{ }^{3 *}$. In terms of country ranking, Slovenia is a leading country, while Estonia and Cyprus share the last position. Column 2 offers three groups of countries: 1) countries with a high $\mathrm{RSPI}_{\ln }{ }^{4 *}$ score (the Netherlands (0.625), Germany (0.614) and Slovenia (0.539)); 2) countries with an average $\mathrm{RSPI}_{\ln }{ }^{4 *}$ score (from United Kingdom (0.428) to Ireland (0.320)) and 3) countries having a low $\mathrm{RSPI}_{\ln }{ }^{4 *}$ score (from Austria (0.303) to Cyprus (0.000)). Finally, Column 3 shows the country ranking according to the value of a composite index based on 5 indicators ( $\mathrm{RSPI}_{\mathrm{ln}}{ }^{5 *}$ ). Comparing this ranking with the ranking in Column 4 (RSPI), differences are spotted in the column with the United Kingdom and France, which belong to the group of countries with the average $\mathrm{RSPI}_{\ln }{ }^{5 *}$ score, while Finland belongs to the countries having a low $\mathrm{RSPI}_{\ln }{ }^{4 *}$ score. The analysis of changes in country ranking in relation to the final ranking of the countries based on the value of RSPI leads to the following results given in (Fig. 2.). 
Fig. 2.

Final country ranking variations depending on $\operatorname{RSPI}_{\ln }{ }^{*}$

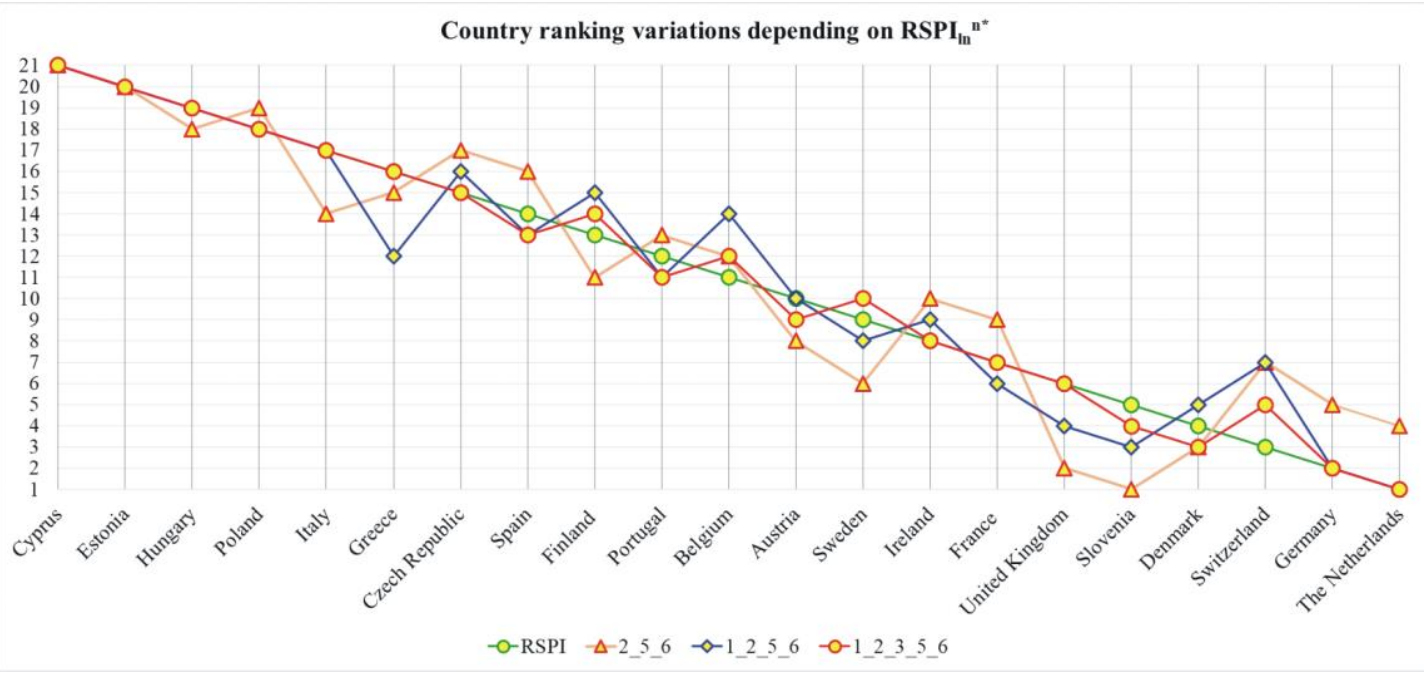

The similarity in country ranking on the basis of values of $\mathrm{RSPI}_{\mathrm{ln}}{ }^{*}$ and the ranking on the basis of RSPI values is considerable. This is proven by the values of standard deviations of all ranks, given in Appendix B.1, Column 5. The matching rate of these values is higher if the calculation of a road safety performance index is made on the basis of a larger number of indicators. Two countries whose ranking is consistent across different combinations have been singled out. They are: Estonia and Cyprus, while some countries sustained changes in their positions for only one place (Poland and Hungary), by adding certain indicators into the calculation. The remaining countries largely deviate in ranks, having therefore the most unstable standing (change in two or more positions), for example Slovenia (5 positions), Switzerland (4 positions), Belgium (4 positions), etc. The most essential differences amongst the rankings are observed for Finland (between $11^{\text {th }}$ and $15^{\text {th }}$ place), Sweden (between $6^{\text {th }}$ and $10^{\text {th }}$ place) and Slovenia (between $1^{\text {st }}$ and $5^{\text {th }}$ place).

As the country ranking matching rate is very high, regardless of the selected combination of most significant indicators, the correlation strength between the mortality rate and the Human Development Index (HDI), and the road safety performance indicators (RSPI) and $\mathrm{RSPI}_{\ln }{ }^{3 *}, \mathrm{RSPI}_{\ln }{ }^{4 *}$ and $\mathrm{RSPI}_{\ln }{ }^{{ }^{*}}$ has been calculated. A high value of correlation coefficient is shown in Table 5.2.

\section{Table 5.2}

Spearman's correlation of a road safety performance index with a limited number of indicators with the mortality rate and the Human Development Index

\begin{tabular}{|c|c|c|c|c|c|c|}
\hline & & & RSPI & $\operatorname{RSPI}_{\ln }{ }^{3 *}: 2 \_5 \_6$ & $\mathrm{RSPI}_{\ln }{ }^{4 *}: 1 \_2 \_5 \_6$ & $\operatorname{RSPI}_{\mid n}{ }^{5 *}: 1 \_2 \_3 \_5 \_6$ \\
\hline \multirow{5}{*}{$\begin{array}{l}\text { Spearman's } \\
\text { rho }\end{array}$} & Mortality rate & \multirow{2}{*}{$\begin{array}{l}\text { Correlation } \\
\text { Coefficient }\end{array}$} & $-.685^{* *}$ & $-.727^{* *}$ & $-.615^{* *}$ & $-.643^{* *}$ \\
\hline & HDI & & $.714^{* *}$ & $.633^{* *}$ & $.651^{* *}$ & $.689^{* *}$ \\
\hline & & Sig. (1-tailed) & .000 & .000 & .000 & .000 \\
\hline & & $\mathrm{N}$ & 21 & 21 & 21 & 21 \\
\hline & \multicolumn{6}{|c|}{ ** Correlation is significant at the 0.01 level (1-tailed). } \\
\hline
\end{tabular}

Looking at the values of correlation coefficient among certain factors in Table 5.2, it can be noticed that $\mathrm{RSPI}_{\mathrm{ln}}{ }^{3 *}: 2 \_5 \_6$ correlates more strongly with the mortality rate when compared to the RSPI. The remaining values of the composite index $\mathrm{RSPI}_{l_{n}}{ }^{*}: 1 \_2 \_5 \_6$ and $\mathrm{RSPI}_{\mathrm{ln}^{5}}{ }^{*}: 1$ 1_2_3_5_6 have a somewhat lower correlation rate. Regardless of the selected combination for the calculation of the composite index, the strength of the correlation with the final outcomes (in this case: mortality rate) and the RSPI is significant. Spearman's correlation coefficient is used to evaluate the degree of consistency between the RSPI and $\mathrm{RSPI}_{l n}{ }^{\mathrm{n}}$ ranking with the HDI ranking. 
Table 5.3

Spearman's correlations of the rankings among other measures and Wilcoxon Signed Ranks Test

\begin{tabular}{|c|c|c|c|c|c|}
\hline & & & $\begin{array}{r}\text { Ranking } \mathrm{RSPI}_{\ln }{ }^{3}{ }^{*}: \\
2 \_5 \_6\end{array}$ & $\begin{array}{r}\text { Ranking RSPI }{ }^{4 *}{ }^{*}: \\
1 \_2 \_5 \_6\end{array}$ & $\begin{array}{r}\text { Ranking } \mathrm{RSPI}_{\mathrm{ln}}^{5^{*}} \text { : } \\
1 \_2 \_3 \_5 \_6\end{array}$ \\
\hline \multirow[t]{5}{*}{ Spearman's rho } & $\begin{array}{l}\text { RSPI } \\
\text { Ranking }\end{array}$ & Correlation & $.926^{* *}$ & $.961^{* *}$ & $.992^{* *}$ \\
\hline & & Sig. (1-tailed) & .000 & .000 & .000 \\
\hline & & $\mathrm{N}$ & 21 & 21 & 21 \\
\hline & & & \multicolumn{3}{|c|}{$* *$ Correlation is significant at the 0.01 level (1-tailed) } \\
\hline & & & $\begin{array}{r}\text { Ranking RSPI }{ }^{3}{ }^{3 *}: \\
2 \_5 \_6\end{array}$ & $\begin{array}{r}\text { Ranking RSPI }{ }^{4}{ }^{4}: \\
1 \_2 \_5 \_6\end{array}$ & $\begin{array}{r}\text { Ranking } \mathrm{RSPI}_{\mathrm{ln}}{ }^{5 *} \text { : } \\
1 \_2 \_3 \_5 \_6\end{array}$ \\
\hline \multirow{4}{*}{$\begin{array}{l}\text { Wilcoxon Signed } \\
\text { Ranks Test }\end{array}$} & RSPI & $\mathrm{z}$ & $-.020^{\mathrm{a}}$ & $-.071^{\mathrm{a}}$ & $.000^{\mathrm{a}}$ \\
\hline & Ranking & & & & \\
\hline & & Asymp. Sig. (2-tailed) & .984 & .941 & 1.000 \\
\hline & & & & \multicolumn{2}{|c|}{ a. Based on positive ranks } \\
\hline
\end{tabular}

The results have shown that a road safety performance index and a road safety performance index with a limited number of indicators, irrespective of indicator combination, have a very strong positive correlation with the HDI (RSPI, $r=.714, p<.01 ; \operatorname{RSPI}_{\ln }{ }^{3 *}, r=.633, \mathrm{p}<.01 ; \operatorname{RSPI}_{\ln }{ }^{4 *}, \mathrm{r}=.651, \mathrm{p}<.01, \mathrm{RSPI}_{\ln }{ }^{{ }^{*}}, \mathrm{r}=.689$, $\mathrm{p}<001$ ). Matching of countries' ranking on the basis of RSPI values and values of $\mathrm{RSPI}_{l_{n}}{ }^{3 *}, \mathrm{RSPI}_{\ln ^{4}}{ }^{*}$ and $\operatorname{RSPI}_{1 n}{ }^{5 *}$ is expressed in the correlation coefficient value and the Wilcoxon Signed Ranks Test (Table 5.3). The strength of correlation among countries' rankings depending on the indicator combination is extremely large and ranges from $r=.926$ to $r=.992$. Furthermore, the Wilcoxon Signed Ranks Test shows that there is no statistically significant change in the ranking of countries and that the value of a road safety performance index with a limited number of indicators is reliable for cross-country comparisons and for defining earlier goal-oriented actions.

\subsection{The most contributing indicators per country and prioritized monitoring phases}

Large correlations identified between the calculated road safety performance index with a limited number of indicators and the mortality rate and the HDI show that it is possible to describe the road safety situation and compare the countries, in a reliable manner, by using only a smaller number of indicators concerned. Matching of countries' rankings in the function of a change of indicators included in the road safety performance index is considerable.

Modern methods of monitoring road safety and international comparisons most often refer primarily to the selection of those indicators that need monitoring at the territory level. That's because its purpose is international benchmarking (between countries). In this respect, it will be necessary to harmonize the number of indicators included in a road safety performance index and their definitions (for example, indicators such as: various SPIs for the risk domain of "alcohol", such as: percentage of drivers with the BAC above the legal limit, number of roadside police alcohol tests per 1,000 population, percentage of fatalities involving at least one driver impaired by alcohol, etc.), as well as the manner and quality of collected data. Finally, the biggest problem occurring in real life is the lack of the periodical monitoring of road safety performance indicators in majority of countries concerned. Thus, the policy makers are not able to accurately define their priorities for action and their counter-measures might not be effective either.

The influence of indicators differs from country to country. In Austria, for example, the most influential indicator belongs to the risk domain: alcohol; in Belgium- to the risk domain: roads; in Germany- to the risk domain: protective system, etc. In order to provide the standardization of indicators, a comparison of the values of a road safety performance index based on the most contributing indicators per country and the values of a road safety performance index with a limited number of indicators has been made and shown below. As it was mentioned at the beginning of the paper, the most contributing indicators per country are a combination of certain indicators having the largest pie share (i.e. the product of the indicator value and 
the indicator weight) in the overall road safety performance index score, or indicators having obtained the highest weights during the optimization of results.

Table 5.4 gives an overview of the most contributing indicators per country. Phases of indicator introduction (recording) are also given and are defined according to the influence that each indicator has on the value of a road safety performance index. For example, the first three indicators having the highest pie share in Austria are the "protective system, roads and trauma management" indicators, which gives the value of $\mathrm{RSPI}_{\mathrm{mci}}{ }^{3}: 3 \_5 \_6=0.335$. The first next indicator that is a part of a combination offering the highest value to the road safety performance indicators based on the most contributing indicators per country is the "speed" indicator $\left(\operatorname{RSPI}_{\mathrm{mil}}{ }^{4}: 2 \_3 \_5 \_6=0.405\right)$. Finally, the indicator relating to the "alcohol" makes a combination of indicators offering the closest value to the road safety performance indicators based on the most contributing indicators per country $\mathrm{RSPI}_{\mathrm{mci}}{ }^{5}$ : 1_2_3_5_6=0.440 (representing $95.44 \%$ of the total value of the RSPI for Austria). Based on these results, the indicator monitoring phases in Austria can be easily prioritized as follows: 1) protective systems, roads and trauma management should be monitored in the first phase, 2) indicator "speed" belongs to the second phase, and 3) indicator relating to "alcohol" will follow in the third phase.

Similar analyses can be made for all the countries concerned, with the exception of Cyprus and Estonia (these two countries had the worst results in terms of optimization). Due to significant changes in dominant indicators, it is interesting to analyze the most contributing indicators for France. A combination of "alcohol, vehicle and roads" indicators offers the highest value of $\mathrm{RSPI}_{\mathrm{ln}^{3}}{ }^{1} 1 \_4 \_5=0.395$ (which is $73.28 \%$ of the total value of the RSPI for France). The next indicators in a combination are "speed and trauma management" indicators and are more influential than the indicator "alcohol" (this indicator is excluded from the calculation of the road safety performance index). This group of indicators offers the value of $\mathrm{RSPI}_{\mathrm{mci}}{ }^{4}: 2 \_4 \_5 \_6=0.477$ (which is $88.50 \%$ of the total value of the RSPI for France). Within the value of RSPI mci $^{5}: 1 \_2 \_3 \_4 \_5=0.526$ (which is $97.59 \%$ of the total value of the RSPI), there was a rotation in terms of indicator's domination (indicator "alcohol and protective system" has excluded the "trauma management" indicator from the calculation).

Also, Table 5.4 shows the overview of frequency of certain most contributing indicators per country. Looking at the column $\mathrm{RSPI}_{\mathrm{mci}^{3}}{ }^{3}$, it is obvious that the most frequent combinations of indicators are: 3_5_6 (Austria, Belgium, Denmark and Italy, (marked with*)) and 1_2_3 (Czech Republic, the Netherlands, Greece and Poland, (marked with **)). Combinations of dominant indicators are different in the remaining countries. This has been expected because an optimization model has been created for each country separately. The situation is a bit different with the $\mathrm{RSPI}_{\mathrm{mci}}{ }^{4}$. The most frequent combinations are those with: 1_2_3_4 (Czech Republic, Finland and Poland, (marked with *)) and 1_2_3_5 (Germany, the Netherlands and Spain, (marked with $* *)$ ). Other countries (two in each group) are grouped according to the following combinations: $2 \_3 \_5 \_6 ; 3 \_4 \_5 \_6 ; 1 \_2 \_4 \_6$ and 1_2_3_6. In the last column with the RSPI mci $^{5}, 12$ countries have been grouped into the 2 most frequent groups with six countries each: 1) 1_2_3_4_6, countries: Czech Republic, Finland, Ireland, Poland, Portugal and Sweden, (marked with *); 2) $1 \_2 \_3$ _5_6, countries: Austria, Denmark, Germany, the Netherlands, Slovenia and Spain, (marked with **). Other countries are grouped into two groups with 3 countries each.

\section{Table 5.4}

The most contributing indicators per country and results of the optimization method

\begin{tabular}{|c|c|c|c|c|c|c|}
\hline & \multirow[b]{2}{*}{$\begin{array}{c}\text { RSPI }_{\mathrm{mci}^{3}}(\% \text { of } \\
\text { RSPI value })\end{array}$} & \multirow[b]{2}{*}{$\begin{array}{c}\text { RSPI }_{\text {mci }}{ }^{4}(\% \text { of } \\
\text { RSPI value })\end{array}$} & \multirow[b]{2}{*}{$\begin{array}{c}\text { RSPI }_{\text {mi }}{ }^{5} \text { (\% of RSPI } \\
\text { value) }\end{array}$} & \multicolumn{3}{|c|}{$\begin{array}{l}\text { Results of optimization method } \\
\text { (Prioritized monitoring phases per } \\
\text { country) }\end{array}$} \\
\hline & & & & $1^{\text {st }}$ phase & $2^{\text {nd }}$ phase & $3^{\text {rd }}$ phase \\
\hline Austria & 3_5_6 $(72.94 \%) *$ & 2_3_5_6 (87.84\%) & 1_2_3_5_6 (95.54\%) ** & 3_5_6 & 2 & 1 \\
\hline Belgium & 3_5_6 $(77.40 \%) *$ & 3_4_5_6 (92.30\%) & 1_3_4_5_6 (100.00\%) & 3_5_6 & 4 & 1 \\
\hline Cyprus & & & - & - & - & - \\
\hline Czech Republic & 1_2_3 (84.52\%) ** & 1_2_3_4 (96.30\%) * & 1_2_3_4_6 $(98.50 \%) *$ & 1_2_3 & 4 & 6 \\
\hline
\end{tabular}




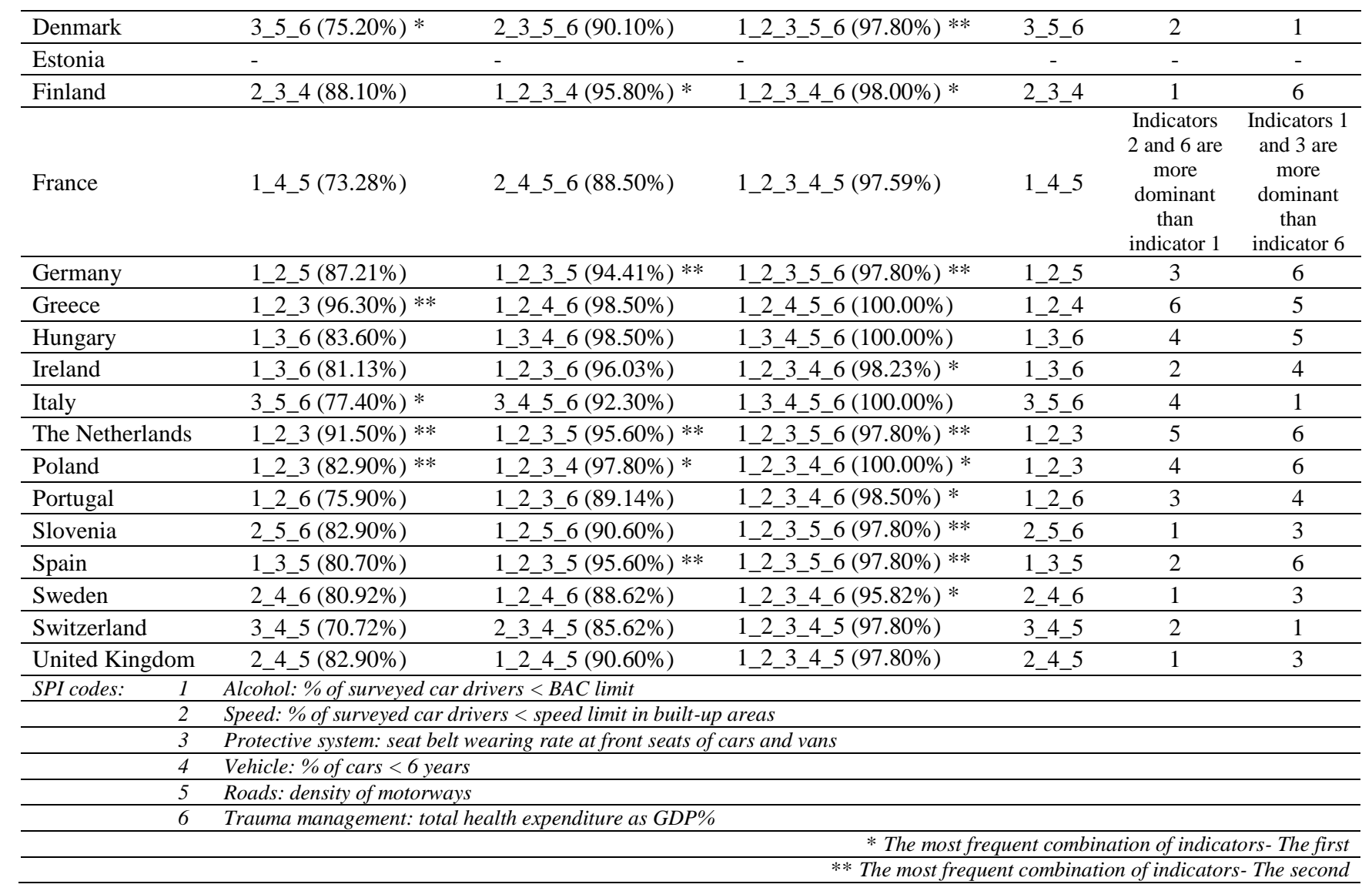

In order to standardize (select indicators) and more easily compare the observed countries, a correlation has been set between the road safety performance indicators based on the most contributing indicators per country $\left(\mathrm{RSPI}_{\mathrm{mci}}{ }^{\mathrm{n}}\right)$ and the value of a road safety performance index for the most frequent combinations of indicators (marked with * and $* *$, Table 5.5). The correlation strength differs depending on the indicator combination. For the purpose of standardization in the process of indicator selection, the combinations having a stronger correlation value have been selected as follows: $1 \_2 \_3, \mathrm{r}=.900 ; 1 \_2 \_3 \_5, \mathrm{r}=.926$ and 1_2_3_5_6, $\mathrm{r}=.991$. In all three cases, the correlation strength is very significant when compared to the value of Spearman's correlation coefficient, $\mathrm{r} \geq .900$ (Table 5.5).

\section{Table 5.5}

Spearman's correlation coefficients of the Road Safety Performance Indicators based on the most contributing indicators per country $\left(\mathrm{RSPI}_{\mathrm{mci}}{ }^{\mathrm{n}}\right)$ and the Road Safety Performance Index for the most frequent indicator combinations (based on Table 5.4.).

\begin{tabular}{|c|c|c|c|c|c|c|c|c|}
\hline & & & $\begin{array}{c}\operatorname{RSPI}_{\ln } 3^{*}: \\
\quad 1 \_2 \_3\end{array}$ & $\begin{array}{c}\text { RSPI In }^{3 *}: \\
\text { 3_5_6 }\end{array}$ & $\begin{array}{c}\operatorname{RSPI}_{\ln } 4^{*}: \\
\text { 1_2_3_5 }\end{array}$ & $\begin{array}{c}\operatorname{RSPI}_{\ln }{ }^{4 *}: \\
1 \_2 \_3 \_4\end{array}$ & $\begin{array}{l}\operatorname{RSPI}_{\ln } 5^{*}: \\
\text { 1_2_3_5_6 }\end{array}$ & $\begin{array}{l}\text { RSPI }{ }_{\text {ln }}^{5 *}: \\
\text { 1_2_3_4_6 }\end{array}$ \\
\hline \multirow{6}{*}{$\begin{array}{l}\text { Spearman's } \\
\text { rho }\end{array}$} & \multirow{6}{*}{$\begin{array}{l}\text { Correlation } \\
\text { Coefficient }\end{array}$} & RSPI $_{\mathrm{mci}^{3}}{ }^{3}$ & $.900^{* * *}$ & $.573^{* *}$ & & & & \\
\hline & & RSPI $_{\mathrm{mci}}{ }^{4}$ & & & $.926^{* *}$ & $.845^{* *}$ & & \\
\hline & & RSPImci $^{5}$ & & & & & $.991^{* * *}$ & $.953^{\text {** }}$ \\
\hline & & Sig. (1-tailed) & .000 & .000 & .000 & .000 & .000 & .000 \\
\hline & & $\mathrm{N}$ & 21 & 21 & 21 & 21 & 21 & 21 \\
\hline & & & & & Correlation & is significant & at the 0.01 les & vel (1-tailed). \\
\hline
\end{tabular}

\section{Table 5.6}

Wilcoxon Signed Ranks Test between countries' rankings based on the values of RSPI ${ }_{\text {mci }}{ }^{n}$ and countries' rankings based on the values of $\mathrm{RSPI}_{\ln }{ }^{\mathrm{n}}$ for the most frequent indicator combinations and with the higher correlation coefficient (based on Table 5.5). 


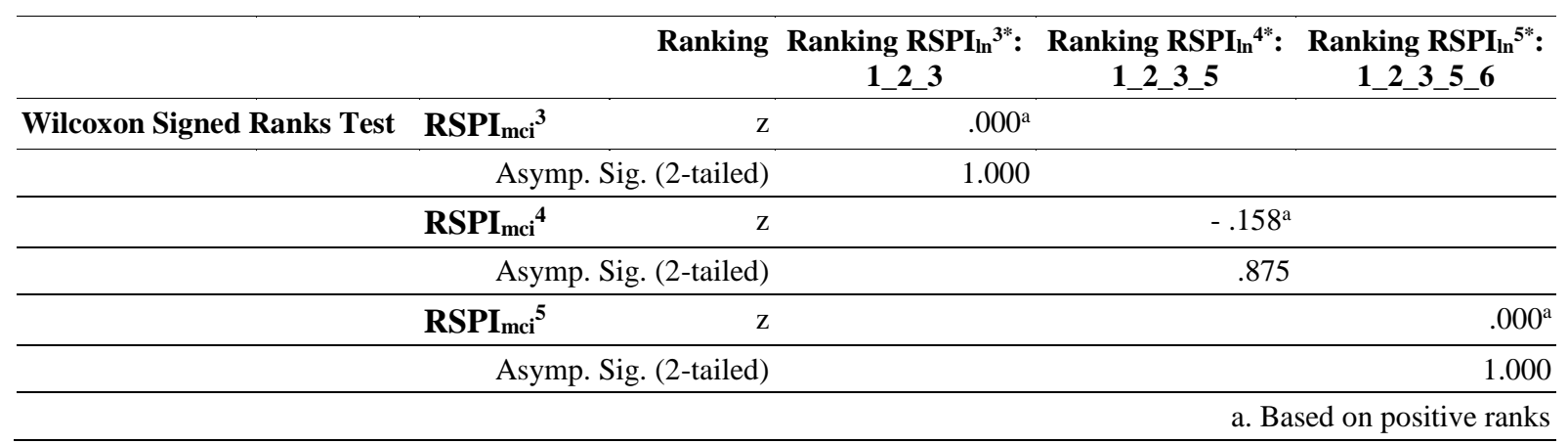

Therefore, the value of the road safety performance indicators based on the most contributing indicators per country (RSPI mi $^{n}$ ) correlates very strongly with the values of the road safety performance index with a limited number of indicators $\left(\mathrm{RSPI}_{\mathrm{n}^{n}}{ }^{\mathrm{*}}\right)$, for the most frequent indicator combinations. The Wilcoxon Signed Ranks Test shows that there is no statistical significance (the value of Asymp. Sig. (2-tailed) is higher than 0.05 in all cases) in the change of countries' rankings when compared to the RSPI ${ }_{\mathrm{mil}}{ }^{\mathrm{n}}$ (Table 5.6). In order to facilitate the cross-country comparisons according to the road safety performance index with a limited number of indicators and make it represent the actual situation (level) of road safety in a reliable manner, it has been proposed to introduce the phases of indicator monitoring in the following way: 1) Phase 1 will understand the periodical monitoring of indicators relating to "alcohol, speed and protective system"; 2) Phase 2 will encompass periodical monitoring of indicators such as: alcohol, speed, protective system and road, and 3) Phase 3 will include periodical monitoring of all indicators, with the exception of "vehicle" indicator. This has secured the uniformity in the selection of a key list of indicators for international comparisons and in the process of defining the phases of introducing the indicators concerned in all the countries that were subject to this research. The smaller set of significant indicators defined in this way can serve for a fast and simple understanding and monitoring of a road safety situation for the larger number of countries. Reliability and relevance of the identified set of significant indicators and identified key list of indicators that need to be monitored depend on the number of indicators included in the calculation of a road safety performance index with a limited number of indicators, the system of collecting road safety data and the strength of their correlation with the final outcomes. This universal index approach is applicable in cases when a broader comprehensive set of indicators is analyzed, which enables a more accurate identification of weaker points and ranks countries in a more meaningful way.

\section{Discussion}

\subsection{Indicator selection}

Given the complex character of the road safety phenomenon, more and more indicators are being suggested for use in monitoring, evaluating, and comparing the status and progress of road safety (Chen et al., 2016). The type of indicators involved in the calculation of the road safety performance index largely defines its purpose. Firstly, if you want to develop capturing of an enriched picture of road safety or an overall road safety composite index, then it will be desirable to include the comprehensive set of road safety indicators belonging to each hierarchical level of the target hierarchy for road safety (Shen et al., 2011b). In that case, attention should be paid to limitations occurring in the use of qualitative road safety indicators (Gitelman et al., 2010). Secondly, indicators belonging to only one hierarchical level (any one) serve for assessing the system's performances within that level. Using the SPIs, the overall road safety performance picture will be obtained, and will contribute greatly to decision makers when deciding on and defining the earlier goaloriented actions (Hermans, 2009a). Thirdly, the quality of the benchmarking process largely depends on data quality. Increasing the efficiency of road safety benchmarking practices will critically require a common framework for collecting and analyzing exposure data (Chen et al., 2016).

However, choosing appropriate indicators is not an easy task. A selection for each risk domain can be made on the basis of their strengths and weaknesses. Therefore, selection of road safety indicators for the creation of a road safety performance index is a very complex work and requires the compromise between the 
desired (the best needed) and available (the best available) indicators. On one hand, indicators should be measurable, available and relevant (Al Haji, 2007), while on the other hand, they should be reliable, comparable, interpretable and sensitive (Hermans, 2009a). Since the selection of a set of indicators is the most influencing input factor (Hermans et al., 2009b), analyses that are being made should pay attention to their volatile behavior (Gitelman et al., 2010).

Identifying the most significant indicators is based on the principle "best of the best", as indicators involved in the process of calculating a road safety performance index must meet several criteria emerging from the research studies of Al-Haji, 2007; Litman, 2007 and Hermans, 2009a. Regardless of recommendations and proven values of the modern (human) manner of road safety monitoring and management, there are countries that have not developed this system. Although the monitoring of safety performance indicators is very demanding from the point of view of human and financial resources, the method and quality of data collection, these countries will benefit most from the standardization of indicators and selection of a key list of indicators for international comparisons. In case of an analysis of a composite index based on a broader set of indicators, the methodology proposed enables a more accurate a revision of the key list of key areas of action/indicators which is repeated until the final goal has been achieved.6.2. Comparisons of countries' rankings

As shown in Table 5.1, the correlation analysis has shown that all the combinations have a large correlation (Spearman's coefficient rho is over .536) with the RSPI, with the exception of the indicator's combination of "protective system, vehicle and trauma management" that has medium correlation strength. Overall, there exists a high degree of matching (congruence) of indicator's combinations (three, four or five). Based on this, the most significant indicators having the largest correlation with the RSPI values have been identified in this way. Grouping of countries on the basis of values of $\operatorname{RSPI}_{\mathrm{ln}^{n}}{ }^{\text {* }}$ differs significantly and is a consequence of the application of an expert's method of data aggregation (ordered weighting averaging operators), which emphasizes bad performances (by means of an orness restriction). Within the data aggregation method, boundary values of the level of road safety performance index for country grouping (high, average or low) have been calculated. When calculating the values of $\mathrm{RSPI}_{\mathrm{ln}}{ }^{3 *}$, the countries have been divided into two groups (average and low RSPI value based on OWA operators). This is in line with the reasoning behind the methodology used in which the countries having at least two bad indicator values should obtain a low-level road safety performance index. The inclusion of more indicators in the calculations of road safety performance indicators (4 or 5) helps highlight the countries that are obtaining high values of road safety performance indexes.

To further capture the graphical insight into the specific relationship between the rankings, the comparison of countries' rankings, based on the $\mathrm{RSPI}_{l n}{ }^{\mathrm{n}^{*}}$, is illustrated in Fig. 2, where the basic ranking is built on the basis of the RSPI. It can be seen that:

- Overall, the four rankings (RSPI, $\mathrm{RSPI}_{\mathrm{ln}^{3}}{ }^{3 *}, \mathrm{RSPI}_{\mathrm{ln}}{ }^{4 *}$ and $\mathrm{RSPI}_{\ln }{ }^{5 *}$ ) are relatively consistent, with slight deviations across the different combinations of indicators. The ranks of Estonia and Cyprus are consistent across different combinations. At the same time, the rankings of Finland, Sweden and Slovenia are associated with relatively large deviations. Countries whose rankings oscillate by at least one to mostly three positions, depending on indicator combination, are ranked in-between.

- The rankings derived from different combinations of indicators are almost identical to the RSPI rankings. The matching is strongest with the values of $\mathrm{RSPI}_{\mathrm{ln}}{ }^{5^{*}}$, and weakest with the values of $\mathrm{RSPI}_{\mathrm{ln}^{3}}{ }^{3 *}$ which is expected as the value of a road safety performance index is more accurate when a larger number of indicators are involved in the calculation. However, the value of a road safety performance index with a limited number of indicators is reliable and robust enough for international cross-country comparisons as it provides an adequate, simple and efficient way of road safety monitoring, which, on the other hand, generates actions for the development of a sustainable system of periodical measuring of indicators in low-ranked territories. 
Validity of a road safety performance index with a limited number of indicators can be compared to the country ranking made according to the values of the mortality rate and the Human Development Index (HDI), as a relevant reference (Chen et al., 2016). Moreover, an increase in the human development index score (representing a long and healthy life, knowledge and a decent standard of living) is associated with an increase in road safety performance index score. In general, it can be concluded that the developed road safety performance index and road safety performance index with a limited number of indicators are linked with the mortality rate and the human development index. A strong correlation between the $\operatorname{RSPI}_{\ln }{ }^{3 *}$ and the mortality rate $(r=-.727, p=.01)$, confirms the significance of indicators (2_5_6) in cases of scarce or missing data. These three indicators allow for comparisons of a larger number of countries and are sufficient for defining the earlier goal- oriented actions that will serve for road safety improvement. This reinforces the credibility, acceptability and future development of the road safety performance index with a limited number of indicators for this set of European countries. Previous results have been confirmed by the strength of correlation among the rankings of a road safety performance index and road safety performance index with a limited number of indicators. The correlation strength in this case is extremely high and the value of the correlation coefficient is above $r>.926$, (Table 5.3), regardless of which indicator combination is considered. However, the following are the most significant indicators for the 21 country set (Table 5.1):

- Three most significant indicators are "speed, roads and trauma management" (abbr.: 2_5_6), $(\mathrm{r}=.906$, $\mathrm{p}=.01)$

- Four most significant indicators are "alcohol, speed, roads and trauma management" (abbr.: 1_2_5_6), $(\mathrm{r}=.958, \mathrm{p}=.01)$ and

- Five most significant indicators are "alcohol, speed, protective system, roads and trauma management" (abbr.: 1_2_3_5_6), $(\mathrm{r}=.994, \mathrm{p}=.01)$.

Therefore, the most significant indicators ensure the optimum selection of indicators and reliable comparison of the safety performance indicators of countries in conditions of unavailable and scarce data on indicators. Since there is a strong correlation between the RSPI and RSPI ${ }_{l n}{ }^{n}$, it will be possible to identify a common list of indicators for all analyzed countries on the basis of the most contributing indicators per country. This ensures a simpler monitoring of indicators, simple understanding of road safety situation as well as the international comparisons and benchmarking process. Also, the most significant indicators provide the selection of right actions for the improvement of weak points within the road safety system, whose accuracy is increasing with the number of indicators included in an analysis.

\subsection{The most contributing indicators per country with prioritized monitoring phases}

There is a large number of causal factors contributing to road accidents and their severity. Harmonization of indicator definitions at the level of final outcomes is quite enviable and most differences occur with the definition of the "deaths per million vehicle kilometers" indicator. Contrary to this, the SPI level is characterized by a wide range of indicator definitions within each risk domain. Definitions and number of indicators vary, especially in the risk domains such as: alcohol and speed. In order to overcome this limitation, it will be necessary to have consistent definitions of indicators, which will in turn facilitate the interpretation and measurement of indicators in various countries. To that end, numerous authors have recommended the standardization of indicators and selection of a key list of indicators for international comparisons or the benchmarking process. Wegman et al., 2005 recommended developing standardized definitions of such indicators and of data collection procedures in order to achieve unambiguous European data that can be compared at the European level. The authors also recommended that a European standard for such a safety template be developed in order to be used in all European (Union) countries. Al-Haji, 2007 suggested defining the following two types of key lists: the list intended for HMCs (Highly Motorized Countries), with lots of details, and the list intended for LMCs (Less Motorized Countries), that can be used uniformly for most countries. At the margins of the above recommendations, Wegman et al., 2008 defined the core set of basic indicators (12 indicators) and offered the recommendations for developing a standardized terminology for road safety indicators and a composite road safety index. Regardless of the 
previous recommendations that concern the standardization of indicators and selection of a key list of indicators, it is very demanding for a large number of countries to measure and monitor the widest possible range of safety performance indicators. A more purposeful and more accurate country comparison is obtained with the development of a decent system for road safety data collection and a harmonized methodology for measuring and monitoring a specified set of indicators.

The results in (Table 5.5 and Table 5.6) have shown that it is possible to identify a group of indicators representing in a credible way the road safety situation in countries that are subject to analysis and securing a high level of accuracy of their comparisons. The correlation analysis has shown that there is a strong positive relation between the Road Safety Performance Index based on the most contributing indicators per country and the road safety performance index with a limited number of indicators. Also, the Wilcoxon Signed Ranks Test has shown that there is no statistically significant difference between countries' rankings based on the above mentioned road safety performance indexes. Based on this, proposed methodology can be applied at the national level, for comparisons of regions, police departments, local self-government units, etc. and at international level (especially in undeveloped and developing countries). From the practical point of view, the application of the proposed methodology can be observed through two aspects: 1) application of methodology in countries that have established the process of measuring and monitoring of indicators, and 2) application of methodology in countries that have not established a stable process of measuring and monitoring of indicators.

- The methodology used in the first group of countries enables identification of the most significant indicators with each measurement and revision of the key list of indicators that should be measured in the future. It can be expected that the influence of certain indicators over time is likely to change due to undertaken activities whose aim is to improve the most significant indicators identified and

- The methodology used in this study and results thereof obtained in the second group of countries offer guidelines for identification of the most important indicators that need to be surveyed. From a practical point of view, this is particularly beneficial in cases of a lack of budgetary funds or other resources for measuring a larger number of indicators in a country's territory.

Therefore, the results have shown that it is possible to very precisely calculate the road safety performance index with a limited number of indicators and make the country ranking in that way. In order to facilitate the comparison of countries that were the subject of analysis, the authors have suggested the monitoring of safety performance indicators in the following way: in Phase 1 of the monitoring, the countries will have to monitor the indicators relating to alcohol, speed and protective systems; in Phase 2, it is recommended to introduce indicators concerning the roads, while the last phase - Phase 3 will have to see the introduction of indicators relating to trauma management. This will help achieve the standardization of indicators and selection of a key list of indicators that need to be monitored and that are involved in the calculation of a road safety performance index in all the countries concerned.

\section{Concluding remarks}

\subsection{Main recommendations for a meaningful road safety performance index}

A road safety performance index is most often used for cross-country comparisons, understanding of road safety situation, benchmarking process, defining the earlier goal- oriented actions and offering support to decision makers to know which road safety topics they perform well or badly as a basis of improvements. The value of a road safety performance index depends mostly on selected indicators, weight allocations and data aggregations, as well as on the strength of correlation between the indicators and final outcomes. Given the purpose of the RSPI and the factors that have the highest impact on its value and quality, the following are the main recommendations for a meaningful road safety performance index:

- Harmonize the procedures and methodologies intended for the measuring of safety performance indicators with the best practices; 
- Provide conditions for development of a periodical system of indicator measuring with a defined list of basic and additional indicators whose monitoring demands field research or whose values can be taken over from international databases;

- Analyze the relationship (the correlation strength) of measured indicators and the final outcomes indicators;

- Analyses were performed on the collected indicator data set in order to gain more insight into each indicator separately (univariate analysis) as well as into the structure and interrelationships of the whole indicator set (multivariate analysis);

- Make the calculation of road safety performance index on the basis of the largest possible number of indicators with the greatest relationship with the final outcomes indicators and

- Use the acquired knowledge regarding data preparation, weighting and aggregation methods and robustness testing for the calculation of a road safety performance index depending on the purpose of a composite index.

Since the availability of data concerning the values of same indicators for a larger number of countries, in a defined time period is limited, the number of indicators included in a comprehensive set of indicators may vary. A road safety performance index obtained on the basis of a broader set of indicators provides a more accurate identification of good and poor road safety points on the territories. However, a road safety performance index with a limited number of indicators (obtained on the basis of a narrower comprehensive set of indicators) provides an efficient way to understand road safety and is an important driver for the development of a sustainable system of periodical measuring of indicators. With the aim to more accurately identify the most significant indicators, it will be necessary to tend to expand the set of identical indicators for a larger number of countries (especially of low-ranked countries), using the principle of including the next best indicator out of the most significant ones.

\subsection{Conclusions and future research}

The road safety performance index is a quality tool used in road safety to make country comparisons, identify the "best-in-class" practices and define the earlier goal-oriented actions. Also, a road safety performance index serves to policymakers to help them recognize and understand the road safety related problems. Within the methodology for calculating a road safety performance index, selection of indicators represents the most requiring work and has the strongest influence on the composite index value. Simply said, the value of a road safety performance index largely depends on the level, quality, data collection method and type of indicators. From a theoretical point of view, a larger number of indicators provide a road safety performance index of higher quality by means of which decision makers are able to more precisely define the earlier goal-oriented actions. Or, by recording a broader comprehensive set of SPIs it is possible to more precisely identify the strengths and weaknesses of a road safety system in a country. However, from the practical point of view, a need arises for the calculation of a road safety performance index with a limited number of indicators which provides comparisons of a sufficient quality used for the biggest possible number of countries and an efficient way of road safety monitoring. A scientifically sound and appropriate methodology for the creation of a road safety performance index with limited number of indicators $\left(\mathrm{RSPI}_{l \mathrm{n}}{ }^{\mathrm{n}}\right)$ that can be used for the monitoring, comparison of road safety performance among countries and standardization of indicators has been developed in this paper. Also, this paper shows the influence of safety performance indicators on the value of a road safety performance index with a limited number of indicators. The results have revealed that comparisons of countries on the basis of a limited number of indicators, i.e. of the most significant indicators, can be made in an accurate manner and with an acceptable level of reliability. Comparisons of results (comparison of countries' rankings) verify the robustness of the most significant indicators and improve the credibility and interpretability of the road safety performance index with a limited number of indicators. The second part of the analysis has identified the most contributing indicators per country. By comparing the values of the road safety performance index obtained on the basis of the most contributing indicators per country with the values of the road safety performance index with a limited number of indicators, the indicators that need monitoring in all the 
analyzed countries have been thus identified. This is the way in which indicators common to all the countries have been identified. This has enabled an easier and more practical cross-country comparison and simple and fast understanding of road safety situation on a territory. Also, a road safety performance index with a limited number of indicators obtained on the basis of a broader comprehensive set of indicators most importantly helped to make a more precise identification of weak road safety points on the territories, and with the learning from meaningful references in terms of policy making, target settings and developing of countermeasures. The concept of identifying the most significant indicators for all countries together contributes to the standardization of indicators and the road safety performance index as it provides a uniform monitoring and comparison in terms of definitions and the way in which they are recorded and analyzed. The optimization of selected indicators contributes to the practicality and resource saving in the monitoring process, provides an adequate and efficient way of road safety monitoring and understanding as well as an important driver for the development of a sustainable system of periodical indicator measurement in low-ranked territories. Finally, the results obtained by using the methodology for calculating the $\mathrm{RSPI}_{\ln }{ }^{\mathrm{n}}$ can encourage a larger number of countries to start measuring and monitoring at least the most significant indicators so that they could be comparable with other countries where safety performance indicators are already monitored. In conditions of a limited road safety budget, the countries will more easily decide on/opt for investments in the most significant among those important areas of work to which the most important indicators refer to, with the aim to provide more cost-effective and more efficient investments in road safety improvements.

The development of a system for periodical monitoring of road safety indicators and justification of countries' investments in monitoring of the the most significant indicators should be viewed through two limitations: 1) the accuracy of selection of the most significant indicators is increasing proportionally with the number of indicators included (on the basis of multiple indicators included in an analysis, a more accurate identification of the most significant indicators is obtained) and 2) it is very demanding for a large number of countries to measure and monitor the widest possible range of safety performance indicators as it is necessary for them to have a developed decent system of collecting road safety data and harmonized methodologies for measuring and monitoring a specific set of indicators. Also, next limitations of this study are the selection of only one indicator from each risk domain (as pointed out in Gitelman et al., 2010), for only one year. This is particularly visible in the group of indicators relating to speed and alcohol. These indicators have been taken over from the SARTRE (The Social Attitudes to Road Traffic Risk in Europe) project and their values are based on subjective assessments of the respondents.

Further research should include the testing of the road safety performance index value based on other data sets, measured in several time series. In that case, the value of a road safety performance index with a limited number of indicators will be obtained from the larger set of indicators which will ensure a more detailed analysis of contributory factors and a more precise identification of the strengths and weaknesses of a country's road safety system. However, it is acceptable to monitor and compare the countries (regions)on the basis of the minimum number of indicators included in a composite index (in this case, only three indicators), in conditions when availability of data concerning the values of same indicators for a larger number of countries, in a defined time period, is rather limited. . 


\section{Appendix A}

Table A.1

Rescaled data set with weights for each SPI and each country

\begin{tabular}{|c|c|c|c|c|c|c|c|c|c|c|c|c|c|}
\hline \multirow{2}{*}{$\begin{array}{l}\text { SPI code } \\
\text { Country }\end{array}$} & \multicolumn{2}{|c|}{1} & \multicolumn{2}{|c|}{2} & \multicolumn{2}{|c|}{3} & \multicolumn{2}{|c|}{4} & \multicolumn{2}{|c|}{5} & \multicolumn{2}{|c|}{6} & \multirow[b]{2}{*}{ RSPI } \\
\hline & $\mathbf{R}_{\text {alcohol }}$ & $\mathbf{W}_{\text {alcohol }}$ & $\mathbf{R}_{\text {speed }}$ & $\mathbf{W}_{\text {speed }}$ & $\begin{array}{c}\mathbf{R}_{\text {protective }} \\
\text { system }\end{array}$ & $\begin{array}{c}\mathbf{W}_{\text {protective }} \\
\text { system }\end{array}$ & RVehicle & $\mathbf{W}_{\text {vehicle }}$ & $\mathbf{R}_{\text {roads }}$ & $\mathbf{W}_{\text {roads }}$ & $\begin{array}{c}\mathbf{R}_{\text {Trauma }} \\
\text { management }\end{array}$ & $\begin{array}{c}\mathbf{W}_{\text {trauma }} \\
\text { management }\end{array}$ & \\
\hline Austria & 0.881 & 0.040 & 0.667 & 0.103 & 0.649 & 0.211 & 0.494 & 0.042 & 0.317 & 0.403 & 0.355 & 0.202 & 0.461 \\
\hline Belgium & 0.734 & 0.041 & 0.000 & 0.370 & 0.456 & 0.256 & 0.650 & 0.090 & 0.933 & 0.100 & 0.661 & 0.142 & 0.393 \\
\hline Cyprus & 0.000 & 0.000 & 0.000 & 0.590 & 0.702 & 0.000 & 0.000 & 0.410 & 0.467 & 0.000 & 0.177 & 0.000 & 0.000 \\
\hline $\begin{array}{l}\text { Czech } \\
\text { Republic }\end{array}$ & 0.908 & 0.129 & 0.667 & 0.084 & 0.614 & 0.153 & 0.066 & 0.566 & 0.100 & 0.048 & 0.355 & 0.020 & 0.319 \\
\hline Denmark & 0.986 & 0.047 & 0.889 & 0.100 & 0.772 & 0.204 & 0.604 & 0.022 & 0.383 & 0.388 & 0.597 & 0.239 & 0.597 \\
\hline Estonia & 0.927 & 0.007 & 0.000 & 0.392 & 0.614 & 0.008 & 0.003 & 0.317 & 0.017 & 0.277 & 0.000 & 0.000 & 0.000 \\
\hline Finland & 0.986 & 0.028 & 0.667 & 0.260 & 0.860 & 0.101 & 0.321 & 0.164 & 0.017 & 0.425 & 0.339 & 0.023 & 0.357 \\
\hline France & 0.766 & 0.260 & 0.556 & 0.144 & 1.000 & 0.051 & 0.550 & 0.146 & 0.300 & 0.384 & 0.774 & 0.015 & 0.539 \\
\hline Germany & 0.890 & 0.283 & 0.556 & 0.273 & 0.947 & 0.052 & 0.568 & 0.026 & 0.550 & 0.341 & 0.935 & 0.025 & 0.680 \\
\hline Greece & 0.638 & 0.168 & 0.667 & 0.192 & 0.000 & 0.498 & 0.538 & 0.080 & 0.083 & 0.052 & 0.742 & 0.009 & 0.290 \\
\hline Hungary & 0.940 & 0.083 & 0.000 & 0.512 & 0.333 & 0.143 & 0.253 & 0.124 & 0.083 & 0.038 & 0.500 & 0.100 & 0.209 \\
\hline Ireland & 0.885 & 0.146 & 1.000 & 0.070 & 0.789 & 0.177 & 1.000 & 0.010 & 0.033 & 0.249 & 0.323 & 0.348 & 0.486 \\
\hline Italy & 0.665 & 0.033 & 0.000 & 0.377 & 0.544 & 0.137 & 0.498 & 0.086 & 0.350 & 0.228 & 0.500 & 0.138 & 0.288 \\
\hline $\begin{array}{l}\text { The } \\
\text { Netherlands }\end{array}$ & 0.913 & 0.280 & 0.556 & 0.580 & 0.807 & 0.062 & 0.597 & 0.025 & 1.000 & 0.031 & 0.726 & 0.021 & 0.692 \\
\hline Poland & 0.986 & 0.097 & 0.556 & 0.075 & 0.544 & 0.141 & 0.144 & 0.266 & 0.000 & 0.392 & 0.194 & 0.029 & 0.256 \\
\hline Portugal & 0.807 & 0.174 & 0.111 & 0.508 & 0.842 & 0.060 & 0.318 & 0.111 & 0.350 & 0.016 & 0.694 & 0.131 & 0.378 \\
\hline Slovenia & 0.876 & 0.052 & 0.667 & 0.409 & 0.719 & 0.060 & 0.902 & 0.015 & 0.367 & 0.213 & 0.565 & 0.252 & 0.596 \\
\hline Spain & 0.670 & 0.146 & 0.111 & 0.456 & 0.807 & 0.125 & 0.521 & 0.014 & 0.317 & 0.239 & 0.387 & 0.019 & 0.340 \\
\hline Sweden & 1.000 & 0.035 & 0.778 & 0.249 & 0.912 & 0.036 & 0.533 & 0.129 & 0.050 & 0.385 & 0.661 & 0.166 & 0.465 \\
\hline Switzerland & 0.807 & 0.101 & 0.889 & 0.112 & 0.737 & 0.270 & 0.616 & 0.162 & 0.517 & 0.339 & 1.000 & 0.015 & 0.674 \\
\hline $\begin{array}{l}\text { United } \\
\text { Kingdom } \\
\end{array}$ & 0.972 & 0.044 & 0.889 & 0.295 & 0.930 & 0.043 & 0.717 & 0.114 & 0.233 & 0.477 & 0.435 & 0.028 & 0.552 \\
\hline
\end{tabular}




\section{Appendix B}

Table B.1

Ranking of values for RSPI, $\operatorname{RSPI}_{\ln }{ }^{3 *}, \mathrm{RSPI}_{\mathrm{ln}}{ }^{4 *}, \mathrm{RSPI}_{\mathrm{ln}}{ }^{5 *}$ based on the most significant three, four and five SPIs based on OWA operators

\begin{tabular}{|c|c|c|c|c|c|c|c|c|c|c|c|c|c|}
\hline \multirow[b]{2}{*}{ Rank } & \multicolumn{3}{|c|}{ Column 1} & \multicolumn{3}{|c|}{ Column 2} & \multicolumn{3}{|c|}{ Column 3} & \multicolumn{3}{|c|}{ Column 4} & \multirow{2}{*}{$\begin{array}{c}\text { Column } 5 \\
\begin{array}{c}\text { Std. Deviation } \\
\text { of all ranks }\end{array}\end{array}$} \\
\hline & Countries & 2_5_6 & $\begin{array}{l}\text { Level of } \\
\text { RSPI I }^{3{ }^{*}} \\
\end{array}$ & Countries & 1_2_5_6 & $\begin{array}{l}\text { Level of } \\
\text { RSPI In }^{4{ }^{*}}\end{array}$ & Countries & 1_2_3_6_6 & $\begin{array}{l}\text { Level of } \\
\text { RSPI In }^{5^{*}}\end{array}$ & Countries & RSPI & $\begin{array}{l}\text { Level of } \\
\text { RSPI }\end{array}$ & \\
\hline 1 & Slovenia & 0.493 & Average & $\begin{array}{l}\text { The } \\
\text { Netherlands }\end{array}$ & 0.625 & High & $\begin{array}{l}\text { The } \\
\text { Netherlands }\end{array}$ & 0.675 & High & $\begin{array}{l}\text { The } \\
\text { Netherlands }\end{array}$ & 0.692 & High & 1.50 \\
\hline 2 & $\begin{array}{l}\text { United } \\
\text { Kingdom } \\
\end{array}$ & 0.386 & Average & Germany & 0.614 & High & Germany & 0.663 & High & Germany & 0.680 & High & 1.50 \\
\hline 3 & Denmark & 0.380 & Average & Slovenia & 0.539 & High & Denmark & 0.584 & High & Switzerland & 0.674 & High & 1.91 \\
\hline 4 & $\begin{array}{l}\text { The } \\
\text { Netherlands }\end{array}$ & 0.369 & Average & $\begin{array}{l}\text { United } \\
\text { Kingdom }\end{array}$ & 0.428 & Average & Slovenia & 0.581 & High & Denmark & 0.597 & High & 0.96 \\
\hline 5 & Germany & 0.363 & Average & Denmark & 0.426 & Average & Switzerland & 0.571 & High & Slovenia & 0.596 & High & 1.71 \\
\hline 6 & Sweden & 0.323 & Average & France & 0.408 & Average & $\begin{array}{l}\text { United } \\
\text { Kingdom } \\
\end{array}$ & 0.468 & Average & $\begin{array}{l}\text { United } \\
\text { Kingdom }\end{array}$ & 0.552 & High & 1.91 \\
\hline 7 & Switzerland & 0.290 & Low & Switzerland & 0.372 & Average & France & 0.459 & Average & France & 0.539 & High & 1.26 \\
\hline 8 & Austria & 0.268 & Low & Sweden & 0.358 & Average & Ireland & 0.459 & Average & Ireland & 0.486 & Average & 0.96 \\
\hline 9 & France & 0.207 & Low & Ireland & 0.320 & Average & Austria & 0.440 & Average & Sweden & 0.465 & Average & 1.71 \\
\hline 10 & Ireland & 0.190 & Low & Austria & 0.303 & Low & Sweden & 0.391 & Average & Austria & 0.461 & Average & 0.96 \\
\hline 11 & Finland & 0.188 & Low & Portugal & 0.293 & Low & Portugal & 0.343 & Average & Belgium & 0.393 & Average & 1.26 \\
\hline 12 & Belgium & 0.188 & Low & Greece & 0.246 & Low & Belgium & 0.335 & Average & Portugal & 0.378 & Average & 0.96 \\
\hline 13 & Portugal & 0.153 & Low & Spain & 0.232 & Low & Spain & 0.333 & Average & Finland & 0.357 & Average & 1.71 \\
\hline 14 & Italy & 0.149 & Low & Belgium & 0.218 & Low & Finland & 0.302 & Low & Spain & 0.340 & Average & 1.41 \\
\hline 15 & Greece & 0.139 & Low & Finland & 0.215 & Low & $\begin{array}{l}\text { Czech } \\
\text { Republic } \\
\end{array}$ & 0.279 & Low & $\begin{array}{l}\text { Czech } \\
\text { Republic } \\
\end{array}$ & 0.319 & Low & 0.96 \\
\hline 16 & Spain & 0.134 & Low & $\begin{array}{l}\text { Czech } \\
\text { Republic }\end{array}$ & 0.185 & Low & Greece & 0.246 & Low & Greece & 0.290 & Low & 1.89 \\
\hline 17 & $\begin{array}{l}\text { Czech } \\
\text { Republic } \\
\end{array}$ & 0.068 & Low & Italy & 0.171 & Low & Italy & 0.246 & Low & Italy & 0.288 & Low & 1.50 \\
\hline 18 & Hungary & 0.053 & Low & Poland & 0.143 & Low & Poland & 0.219 & Low & Poland & 0.256 & Low & 0.50 \\
\hline 19 & Poland & 0.047 & Low & Hungary & 0.131 & Low & Hungary & 0.179 & Low & Hungary & 0.209 & Low & 0.50 \\
\hline 20 & Estonia & 0.005 & Low & Estonia & 0.011 & Low & Estonia & 0.016 & Low & Estonia & 0.000 & Low & 0.00 \\
\hline 21 & Cyprus & 0.000 & Low & Cyprus & 0.000 & Low & Cyprus & 0.000 & Low & Cyprus & 0.000 & Low & 0.00 \\
\hline
\end{tabular}




\section{Acknowledgments}

The authors would like to thank the Associate Editor, PhD Jeremy Broughton, and several anonymous reviewers for their valuable comments and suggestions, which have been of great help in improving the quality of this paper.

\section{References}

Al- Haji, G. (2007). Road Safety Development Index (RSDI): Theory, Philosophy and Practice. Department of Science and Technology. Linköping http://ir.nmu.org.ua/bitstream/handle/123456789/126470/0bb47fc915be24e29d6a9f7912a5abe3.pdf?sequence=1

University,

Al- Haji, G. (2005). Towards a Road Safety Development Index (RSDI)-Development of an International Index to Measure Road Safety Performance. Department of Science and Technology. Norrköping: Linköping University, http://www.divaportal.org/smash/get/diva2:20332/FULLTEXT01.pdf

Bastos, J. T., Shen, Y., Hermans, E., Brijs, T., Wets, G., and Ferraz, A. C. P. (2015). Traffic fatality indicators in Brazil: state diagnosis based on data envelopment analysis research. Accident Analysis and Prevention, 81, 61-73, doi:10.1016/j.aap.2015.01.024

Bastos, J. T. (2014). Road safety strategic analysis in Brazil: Indicator and index research. Doctoral Thesis, Escola de Engenharia de São Carlos, Universityof São Paulo, São Carlos. Retrieved 2015-09-24, from http://www.teses.usp.br/teses/disponiveis/18/18144/tde-08042015-103747/

Bax, C., Wesemann, P., Goldenbeld, C., Wegman, F., Aarts, L., Gitelman, V., et al. (2012). Developing a Road Safety Index. Deliverable 4.9 of the EC FP7 project project.eu/Deliverables/DaCoTA_D4.9_developing\%20a\%20RSI\%20deliverable.pdf

Charnes A, Cooper WW, Lewin AL, Seiford LM. DEA: Theory, Methodology, and Application. Boston, MA: Kluwer Academic Publishers; 1994.

Charnes, A., Cooper, W., Rhodes, E., 1978. Measuring the efficiency of decision making units. Eur. J. Oper. Res. 2, 429-444

Cherchye, L., Moesen, W., Rogge, N., Van Puyenbroeck, T., Saisana, M., Saltelli, A., Liska, R., Tarantola, S., 2006. Creating Composite Indicators with DEA and Robustness Analysis: The Case of the Technology Achievement Index. Catholic University of Leuven and Joint Research Centre.

Cohen, J. (1988) Statistical Power Analysis for the Behavioral Sciences, 2nd ed. Hillsdale, NJ: Erlbaum.

Cooper WW, Seiford LM, Tone K. DEA: A Comprehensive Text With Models, Application, References and DEA Solver Software. Boston, MA: Kluwer Academic Publishers; 2000.

Cooper WW, Seiford LM, Zhu J. Handbook on Data Envelopment Analysis. Boston, MA: Kluwer Academic Publishers; 2004.

Chen, F., Wu, J., Chen, X., Wang, J., and Wang, D. (2016). Benchmarking road safety performance: Identifying a meaningful reference (best-in-class). Accident Analysis and Prevention, 86, 76-89, doi: doi:10.1016/j.aap.2015.10.018

European Transport Safety Council. (2001). Transport Safety Performance Indicators. Brussels, http://etsc.eu/wpcontent/uploads/Transport-safety-performance-indicators.pdf

European Union Road Federation (2006). European Road Statistics 2006.

Eurostat (2007). Europe in figures: Eurostat yearbook 2006-07. Commission of the European Communities.

Eurostat (2008). Transport database. Retrieved October 16 ${ }^{\text {th }}, 2017$ from http://epp.eurostat.ec.europa.eu.

Farchi, S., Molino, N., Rossi, P. G., Borgia, P., Krzyzanowski, M., Dalbokova, D., et al. (2006). Defining a common set of indicators to monitor road accidents in the European Union. BMC Public Health, 6, 183-195, doi: http://www.biomedcentral.com/1471-2458/6/183

Gitelman, V., Vis, M., Weijermars, W., and Hakkert, S. (2014, June 30). Development of road safety performance indicators for the European Countries. Advances in Social Sciences Research Journal, 1(4), 138-158, http://scholarpublishing.org/index.php/ASSRJ/article/view/302/168

Gitelman, V., Doveh, E., and Hakkert, S. (2010). Designing a composite indicator for road safety. Safety Science, 48, 1212-1224, doi:10.1016/j.ssci.2010.01.011

Hakkert, S., and Gitelman, V. (2007a). Road Safety Performance Indicators: Manual. Loughborough University. Deliverable D3.8 of the EU FP6 project SafetyNet, http://erso.swov.nl/safetynet/fixed/WP3/sn wp3 d3p8 spi manual.pdf 
Hakkert, S., Gitelman, V., and Vis, M. (2007b). Road Safety Performance Indicators: Theory. Loughborough University. Deliverable D3.6 of the EU FP6 project SafetyNet, http://erso.swov.nl/safetynet/fixed/WP3/sn_wp3_d3p6_spi_theory.pdf

Hermans, E., Ruan, D., Brijs, T., Wets, G., and Vanhoof, K. (2010b). Road safety risk evaluation by means of ordered weighted averaging operators and expert knowledge. Knowledge-Based Systems, 23(1), 48-52, doi:10.1016/j.knosys.2009.07.004

Hermans, E., Brijs, T., and Wets, G. (2010a). Bringing structure into road safety evaluation: A hierarchy of indicators. Retrieved November 21, 2014, from University of Hasselt: https://doclib.uhasselt.be

Hermans, E. (2009a). A methodology for developing a composite road safety performance index for cross- country comparasion. $\mathrm{PhD}$ Thesis. University of Hasselt, http://trid.trb.org/view.aspx?id=1152165

Hermans , E., Van den Bosshe, F., and Wets, G. (2009b). Uncertainty assessment of the road safety index. Reliability Engineering and System Safety, 94, 1220-1228, doi:10.1016/j.ress.2008.09.004

Hermans , E., Van Den Bosshe, F., and Wets, G. (2008b). Combining road safety information in a performance index. Accident Analysis and Prevention, 40, 1337-1344, doi:10.1016/j.aap.2008.02.004

Hermans, E., Van Den Bosshe, F., and Wets, G. (2007). Impact of Methodological Choices on Road Safety Ranking. University of Hasselt, https://doclib.uhasselt.be/dspace/handle/1942/10918

Koornstra, M., Lynam, D., Nillson, G., Noordzij , P., Petterson, H.-E., Wegman, F., et al. (2002). SUNflower: A comparative study of the development of road safety in Sweden, the United Kingdom and the Netherlands. Leidschendam: SWOV Institute for Road Safety Research, http://ec.europa.eu/transport/roadsafety_library/publications/sunflower_report.pdf

Intan Suhana, I. S., Hamid, H., Hwa, L. T., and Farhan, A. (2014). Identification of Hazardous Road Sections: Crash Data versus Composite Index Method. IACSIT International Journal of Engineering and Technology, 8(8), 481-486, http://www.ijetch.org/papers/745-T970.pdf

Litman T. Developing indicators for comprehensive and sustainable transport planning. In: Proceedings of the 86th annual meeting of the Transportation Research Board, Washington, DC, 2007.

LTSA. (2000). Road safety strategy 2010. A consultation document. National Road Safety Committee. http://www.ltsa.govt.nz/ publications/rs-framework.html

Nardo, M., Saisana, M., Saltelli, A., and Tarantola, S. (2005a). Handbook on Constructing Composite Indicators: Methodology and user guide. Retrieved November 20, 2014, from OECD Statistics Working Papers 2005/03; OECD Publishing: http://dx.doi.org/10.1787/533411815016

Nardo, M., Saisana, M., Saltelli, A., and Tarantolo, S. (2005b). Tools for Composite Indicators Building. European Communities, http://publications.jrc.ec.europa.eu/repository/bitstream/JRC31473/EUR\%2021682\%20EN.pdf

Organisation for Economic Co-operation and Development (2008). OECD Factbook 2008.

Pallant, J. (2011). SPSS survival manual. McGraw-Hill Education (UK). http://eunacal.org/metodakerkimi/wpcontent/uploads/spss/SPSS_Survival_Manual_4th_Edition.pdf

Pešić, D., Vujanić, M., Lipovac, K., and Antić, B. (2013). New method for benchmarking traffic safety level for the territory. Transport, 28(1), 69-80, doi:10.3846/16484142.2013.781539.

Pešić, D. R. (2012). Developing and improving the method for measuring the level of traffic safety at the territory. PhD Thesis. Faculty of Transport and Traffic Engineering. Belgrade: Faculty of Transport and Traffic Engineering.

Promoting Seat Belt Use, T. L. ETSC Fact Sheet, 2006.

Saisana, M., Saltelli, A., and Tarantola, S. (2005). Uncertainty and sensitivity analysis techniques as tools for the quality assessment of composite indicators. Journal of Royal Statistical Society, 168(2), 307-323, doi: 10.1111/j.1467-985X.2005.00350.x

Saisana, M., and Tarantola, S. (2002). State-of-the-Art Report on Current Methodologies and Practices for Composite Indicator Development. European Communities, http://citeseerx.ist.psu.edu/viewdoc/download?doi=10.1.1.402.5612andrep=rep1andtype=pdf

SARTRE 3 consortium (2004). European drivers and road risk. Inrets.

Shen, Y., Hermans, E., Bao, Q., Brijs, T., Wets, G., and Wang, W. (2015a). Inter-national benchmarking of road safety: state of the art. Transportation research part C: Emerging technologies, 50, 37-50, doi:10.1016/j.trc.2014.07.006

Shen, Y., Hermans, E., Bao, Q., Brijs, T., \& Wets, G. (2015b). Serious injuries: an additional indicator to fatalities for road safety benchmarking. Traffic injury prevention, 16(3), 246-253, http://dx.doi.org/10.1080/15389588.2014.930831

Shen, Y., Hermans, E., Brijs, T., and Wets, G. (2014). Fuzzy Data Envelopment Analysis in Composite Indicator Construction. In A. Emrouznejad, and M. Tavana, Performance Measurement with Fuzzy Data Envelopment Analysis (pp. 89-100). Springer, https://doclib.uhasselt.be/dspace/bitstream/1942/16175/1/shenfuzz.pdf 
Shen, Y., Hermans, E., Ruan, D., Wets, G., Brijs, T., and Vanhoof, K. (2011a). Modeling qualitative data in data envelopment analysis for composite indicators. International Journal of System Assurance Engineering and Management, 2(1), 21-30, http://link.springer.com/article/10.1007/s13198-011-0051-z\#page-1

Shen, Y., Ruan, D., Hermans, E., Brijs, T., Wets, G., and Vanhoof, K. (2011b). A generalized multiple layer data envelopment analysis model for hierarchical structure assessment: A case study in road safety performance evaluation. Expert Systems with Applications, 38, 15262-15272, doi:10.1016/j.eswa.2011.05.073

Vis, M. A., and Eksler, V. (2008). Road Safety Performance Indicators Updated Country Comparisons. Deliverable D3.11a of the EU FP6 project. Loughborough University, http://erso.swov.nl/safetynet/fixed/WP3/sn_wp3_d3p11a_spi_updated_country_comparisons_final.pdf

Vis, M. A. (2005). Deliverable D3.1: State of the art Report on Road Safety Performance Indicators. Loughborough University. SWOV, http://erso.swov.n1/safetynet/fixed/WP3/Deliverable\%20wp\%203.1\%20state\%20of\%20the\%20art.pdf

Wegman, F. and Oppe, S. (2010). Benchmarking road safety performances of countries. Safety Science, 48, 1203-1211, doi:10.1016/j.ssci.2010.02.003

Wegman, F., Commandeur, J., Doveh, E., Eksler, V., Gitelman, V., Hakkert, S., et al. (2008). SUNflowerNext: Towards a composite road safety performance index. Leidschendam: SWOV Institute for Road Safety Research, http://www.swov.nl/rapport/sunflower/sunflowernext.pdf

Wegman, F., Eksler, V., Hayes, S., Lynam, D., Morsink, P., and Oppe, S. (2005). SUNflower+6. A comparative study of the development of road safety in the SUNflower+6 countries: Final report. Leidschendam: SWOV Institute for Road Safety Research, http://www.20splentyforus.co.uk/UsefulReports/SUNflower+6 Final Report.pdf

World Health Organization. (2009). World health statistics 2009.

Yager, R.R. (1988). On ordered weighted averaging aggregation operators in multi-criteria decision making. IEEE Transactions on Systems, Man and Cybernetics, 18 pp. 183-190.

Yager, R.R. (1997). On the inclusion of importances in OWA aggregations. In the ordered weighted averaging operators. Dordrecht: Kluwer Academic Publishers. 